\title{
Thermal Spraying of Oxide Ceramic and Ceramic Metallic Coatings
}

\author{
Martin Erne and Daniel Kolar \\ Institute of Materials Science, Leibniz University of Hannover
}

Germany

\section{Introduction}

Thermal Spraying is called a group of processes by means of that thin ceramic and ceramic metallic (cermet) coatings can be applied on a vast variety of materials, so called substrates. The goal is to reach considerably different characteristics on the surface of the component part regarding the resistance against abrasion and corrosion, the electrical conductivity and many more. This chapter intends to give an overview of the different processes, the processable feedstock materials, the different areas of application and new developments in the field of Thermal Spraying.

\section{Thermal spray processes and coatings' microstructure}

All together thermal spray processes make use of heat and kinetic energy to warm-up and propel feedstock material to build up a coating on the substrate. Often the goal is to melt the feedstock thoroughly due to reach a dense microstructure, but in some cases the feedstock impinges in solid state and is deformed by the kinetic energy as the particles reach supersonic velocity before impact. Dependent on the source of energy distinctly different process characteristics and therefore visibly diverse microstructure and properties of the coatings can be obtained.

In the norm DIN EN 657 "Thermal Spraying" the different processes are distinguished by the means of the energy source. The processes being widely in operation are based on the energy sources flames and electric or gas discharges. Although the lasers assisted spraying techniques are coming more and more into operation, they cover only a small segment compared to the conventional techniques. By means of molten bath and "cold" or, in other terms, kinetic spraying only metallic feedstock can be used. Therefore both processes are not covered in this chapter. In fact the focus of this chapter lies on workings done in the fields of thermal spraying by means of Atmospheric plasma spraying (APS) as well as High velocity oxyfuel spraying (HVOF, see markings in Figure 1 on the following page).

\subsection{Achieving near net shape coatings}

Besides metallic feedstock for their electrical and tribological properties as well as repair purposes many ceramic materials can be sprayed. The commonly used feedstock can be 
divided into oxide ceramics and the embedding of covalent bound materials like carbides and borides in metallic binder phases (so called cermets derived from "ceramic metals"). Besides the different hardness of the hard phase and the two-phase nature of cermet coatings, the feedstock itself is manufactured by totally different production routes. For both the molten and crushed oxide ceramics and the usually agglomerated and sintered cermet powders there is the trend to use finer grain sizes to reach denser and better microstructures of the coatings on the one hand (Gell, M., et al., 2001; Tilmann et al., 2008a). On the other hand with fine feedstock powders near net shape coatings can be sprayed, showing a comparable low surface roughness, both allowing to reduce the costs of finishing workings (Matthäus, G., Wolf, J. \& Ackermann, D., 2010; Tilmann et al., 2008b).

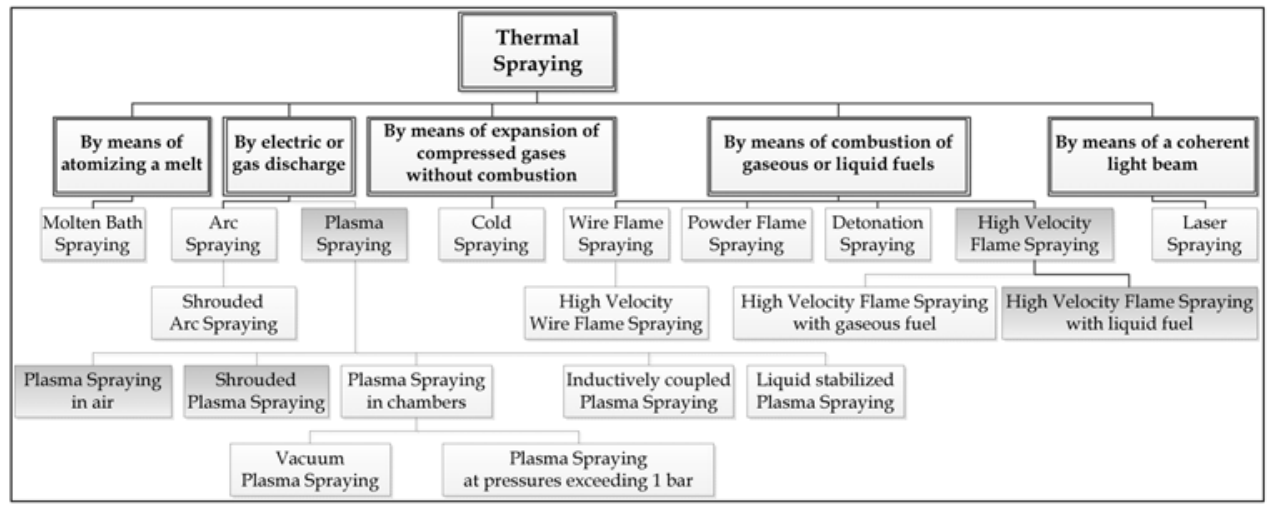

Fig. 1. Classification of Thermal Spray processes with regard to the source of energy (after DIN EN 657 “Thermal Spraying")

In the following the differences in the performance of abrasion and corrosion resistant coatings regarding the deposition efficiency, surface roughness, hardness, porosity, wear behavior and corrosion resistance will be discussed regarding the inset feedstock grain size and the resulting coatings' microstructure. Several feedstock materials typically used for named fields of operation (WC-CoCr 86/10/4, $\mathrm{Cr}_{3} \mathrm{C}_{2}-\mathrm{Ni20Cr} 75 / 25$ and $\mathrm{Cr}_{2} \mathrm{O}_{3}$ ) were considered for developing near net shape coatings. In contrast to grain sizes commonly used in thermal spray processes of up to appr. $50 \mu \mathrm{m}$, the grain sizes of all examined powders were specified with a maximum of $25 \mu \mathrm{m}(-15+5 \mu \mathrm{m},-20+5 \mu \mathrm{m}$ and $25+5 \mu \mathrm{m})$. Different types of conventional and one specialized powder feeder were investigated regarding their abilities of continuous feeding. For the coating experiments the kerosene fuelled HVOF-gun K2 (GTV GmbH, Luckenbach, Germany) was used to apply the carbide based feedstock materials (WC-CoCr and $\mathrm{Cr}_{3} \mathrm{C}_{2}-\mathrm{NiCr}$ ), whereas the conventional APS-gun F4 (Sulzer Metco AG, Wohlen, Switzerland) was used to apply $\mathrm{Cr}_{2} \mathrm{O}_{3}$ coatings. Compared to coatings being sprayed using conventional fractionated feedstock, the coatings based on fine feedstock showed better results concerning their key characteristics. 


\subsection{Comparison of microstructures, phase contents and deposition rates}

The micrographs on the following page show the microstructures obtained by spraying fine feedstock with particle sizes $<25 \mu \mathrm{m}$ (left side) and conventional fractionated feedstock $(-45+5 \mu \mathrm{m}$ in case of chromia and $-45+25 \mu \mathrm{m}$ for the cermets, right hand side).

The parameter settings for the spraying experiments were investigated using methods of designed experiments (for a detailed discussion see chapter 3). After conducting tests regarding a continuous feeding of the different feedstock powders, preliminary test series were conducted to evaluate the effects of the main process parameters regarding the feedstock grain size, the amperage in case of APS and the air-fuel-ratio in case of HVOF, spraying distance and powder feed rate. The results of these experiments were investigated regarding the coatings criteria named at the beginning. For finding optimal parameter sets the economic relevant criteria deposition efficiency and surface roughness were given the highest priority as well as reaching sufficiently high indention hardness at the same time.

The microstructures of the optimum parameter sets for the fine grained feedstock compared to coatings sprayed with conventional fractionated feedstock are shown in Figure 2. The metallographic cross sections of the coatings showed, that the porosity of the coatings can be decreased by processing fine powders. Measurements by means of image analysis revealed, that the ratio of porosity in case of the near net shape coatings is approximately only on quarter to one third compared to the conventional coating systems reaching values of $0.1 \%$ in case of the WC-CoCr coating. At the same time the roughness of the top layers described by the profile parameters roughness average $\left(R_{a}\right)$ and height $\left(R_{Z}\right)$ is also considerably lower. For all fine feedstock powders $R_{a}$ values in the range of 2.5 to $2.7 \pm 0.1 \mu \mathrm{m}$ of the as sprayed coatings could be reached, whereas for the usually applied powders the values were significantly higher with $4.5 \pm 0.3 \mu \mathrm{m}$ in case of chromia and $6.7 \pm 0.4 \mu \mathrm{m}$ for the cermet coatings. Furthermore the uniformity of the coatings is significantly better when spraying the fine feedstock permitting the goal of applying near net shape coatings. But these efforts are accompanied by considerably lower deposition rates caused by lower mass throughputs and the difficult heat transfer to the relative high melting NiCr-matrix in case of HVOF spraying of the $\mathrm{Cr}_{3} \mathrm{C}_{2}-\mathrm{NiCr}$ feedstock. On the other hand this disadvantage can be equalized by the aim of achieving coatings of lower thickness resulting in comparable times for the spraying process for both the fine and the coarse fractionated feedstock.

Then again when spraying the finer powders in the spray process, there is also a higher risk of overheating the small spray particles. In particular the composition of the carbide based coatings can be changed because of decarburization and oxidation effects. The examination of the metallographic cross sections under this aspect showed, that especially the coatings based on fine $\mathrm{Cr}_{3} \mathrm{C}_{2}-\mathrm{NiCr}$ powder showed strong oxidation (see the dark-gray phases in Figure $\mathbf{2} \mathbf{b}$ left hand side). In order to achieve more information about these phase changes the carbide based samples were analyzed by X-ray diffraction. The obtained X-ray diffraction patterns are shown in Figure 3. The pattern of the $\mathrm{Cr}_{3} \mathrm{C}_{2}-\mathrm{NiCr}$ sample sprayed with feedstock $-15+5 \mu \mathrm{m}$ (see lower pattern in Fig. 3 a) shows noticeable $\mathrm{Cr}_{2} \mathrm{O}_{3}$ peaks indicating that a strong oxidation of the spray particles took place during the spray process. Furthermore decarburization effects were also stronger when using the fine powder. In the sample sprayed with the standard feedstock, the dominating carbide phase was $\mathrm{Cr}_{3} \mathrm{C}_{2}$, whereas the other coating was dominated by the lower carbide phase $\mathrm{Cr}_{23} \mathrm{C}_{6}$. For the WC- 
CoCr samples the effect of decarburization was examined by determining the intensity ratio of the strongest $\mathrm{WC}$ in relation to the $\mathrm{W}_{2} \mathrm{C}$ peak $\left(\mathrm{I}_{\mathrm{W} 2 \mathrm{C}(100)} / \mathrm{I}_{\mathrm{WC}(100)}\right.$, see Fig. $\left.3 \mathrm{~b}\right)$. Similar values of 0.22 in case of the fine and 0.17 for the coarser fractionated feedstock were obtained indicating a stronger decarburization when spraying the fine feedstock. Compared to the $\mathrm{Cr}_{3} \mathrm{C}_{2}-\mathrm{NiCr}$ samples these effects of phase chances were quite low.
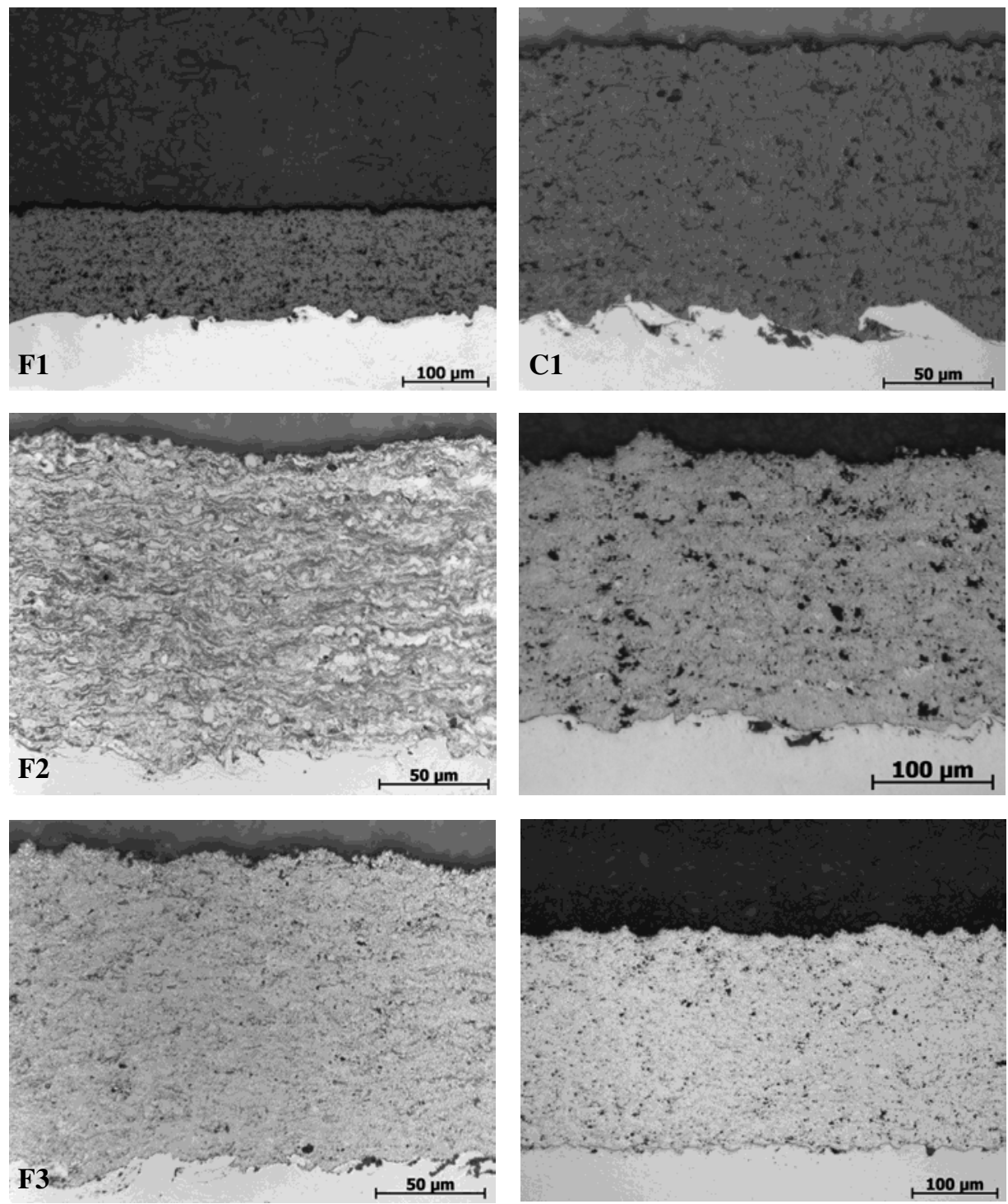

Fig. 2. Comparison of achievable microstructures using fine powder feedstock $<25 \mu \mathrm{m}$ grain size (left) and conventional more coarsely fractionated feedstock $-45+5 / 20$ (right) for $\mathrm{Cr}_{2} \mathrm{O}_{3}$ (a), $\mathrm{Cr}_{3} \mathrm{C}_{2}-\mathrm{NiCr}(\mathrm{b})$ and WC-CoCr (c) 

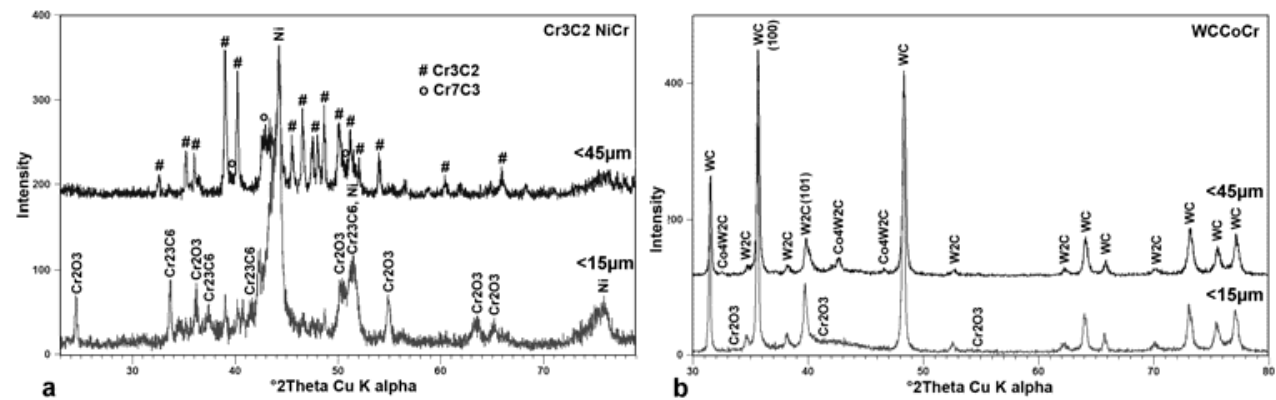

Fig. 3. X-Ray diffraction patterns of $\mathrm{Cr}_{3} \mathrm{C}_{2}-\mathrm{NiCr}(\mathrm{a})$ and $\mathrm{WC}-\mathrm{CoCr}(\mathrm{b})$ coatings

\subsection{Indentation hardness}

One characteristic criterion determining the wear resistance of thermal sprayed coatings is the hardness, which is usually measured by indentation techniques. The Vickers hardness indentation test is well-established both in the course of the quality management of job shops as well as in the characterization of coatings reported in literature. Another technique is the superficial Rockwell hardness testing, by means of that the coatings can be analysed without metallographic preparation. To investigate the suitability of both methods and the influences on the measurement results, a cause-and-effect diagram was established for the indentation testing of thermal spray coatings (see Figure 4). The goal of the workings was the reduction of the variability of the measuring results to enhance the comparability.

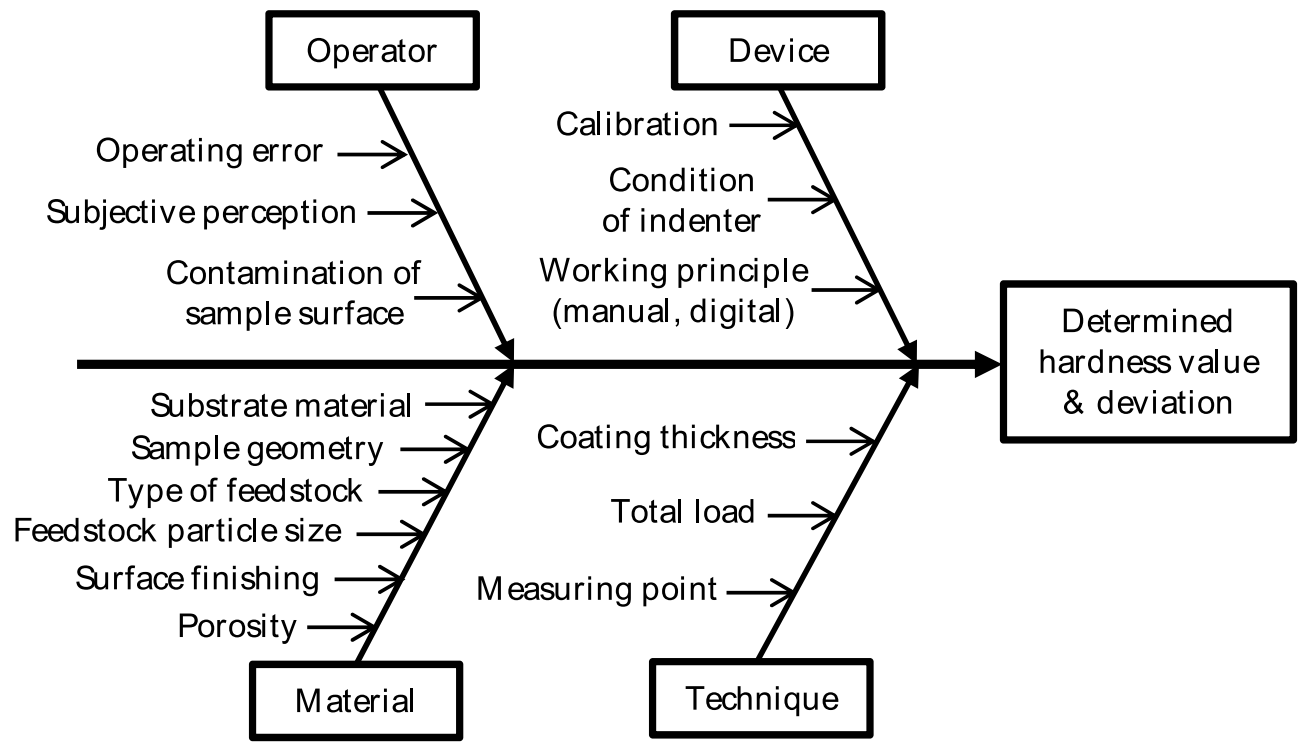

Fig. 4. Cause-and-effect diagram of the indentation hardness measurement of coatings 
A large number of predominantly oxide ceramic and cermet coating systems were investigated concerning the different sources of variation depicted in Figure 4 . In the following especially the influence of the microstructure, the loading force, the inset type of hardness tester and the necessary quantity of measurement repetitions on one sample regarding the increase of the repeatability are discussed. In the following Table 1 the indentation hardness values for the coatings shown in Figure 2 are listed.

\begin{tabular}{|c|c|c|c|c|c|c|c|c|c|c|c|c|c|c|c|c|c|c|}
\hline Feedstock & \multicolumn{6}{|c|}{$\mathrm{Cr}_{2} \mathrm{O}_{3}$} & \multicolumn{6}{|c|}{$\mathrm{Cr}_{3} \mathrm{C}_{2}-\mathrm{NiCr}$} & \multicolumn{6}{|c|}{ WC-CoCr } \\
\hline $\begin{array}{l}\text { Fraction/ } \\
\text { Sample }\end{array}$ & \multicolumn{3}{|c|}{ F1 } & \multicolumn{3}{|c|}{$\mathrm{C} 1$} & \multicolumn{3}{|c|}{ F2 } & \multicolumn{3}{|c|}{$\mathrm{C} 2$} & \multicolumn{3}{|c|}{ F3 } & \multicolumn{3}{|c|}{$\mathrm{C} 3$} \\
\hline${\left.\text { Technique }{ }^{1}\right)}$ & 1 & 2 & 3 & 1 & 2 & 3 & 1 & 2 & 3 & 1 & 2 & 3 & 1 & 2 & 3 & 1 & 2 & 3 \\
\hline Mean & 89,7 & 85,9 & 1222 & 87,4 & 90,2 & 1424 & 87,9 & 87,2 & 1032 & 85,6 & 85,8 & 867 & 87,5 & 86,8 & 1172 & 88,2 & 85,3 & 1245 \\
\hline SD 5 & 1,1 & 1,4 & 45 & 2,6 & 1,9 & 74 & 1,8 & 2,3 & 31,8 & 2,0 & 3,9 & 76 & 2,3 & 2,3 & 26,5 & 4,6 & 1,9 & 148,5 \\
\hline SD 10 values & 1,0 & 1,7 & 37 & 2,3 & 2,0 & 81 & 2,0 & 2,5 & 57,3 & 1,8 & 3,5 & 73 & 1,9 & 2,9 & 84,3 & 3,4 & 2,9 & 142 \\
\hline
\end{tabular}

1Techniques:

1 = Superficial Rockwell HR15N manual

2 = Superficial Rockwell HR15N digital

3 = Vickers HV0.3

Table 1. Comparison of indentation hardness values derived by superficial Rockwell and Vickers testing

The mean values were derived from 10 measurements for each sample and measurement technique. The results of the measurements of different experimental series were investigated regarding their distribution and the appearance of outliers using the span of standard deviation and Grubb's test. In most cases the values are not normal distributed, but also hardly any outlier can be detected. Therefore the goal was chosen to reduce the standard deviation of the measurements as the repeatability between different operators, hardness testing devices etc. is expected to increase with decreasing standard deviation. For first evidence the standard deviations of the first 5 measurements and of 10 measurements were compared to get information about the necessary number of measurements to receive robust results.

The results of the two different types of Rockwell hardness testers (one manual Wilson device and a digital type STRUERS DuraJet with closed loop control of the applied force) do not differ very much. The standard deviation is lower than approximately $4 \%$ of the mean measured value and is often higher when it was calculated from ten values instead of the first five ones. This might be due to influences of the microstructure on the results like unmelted particles in the case of chromia and the bimodal hardness distribution of the cermet type coatings. Furthermore the derived mean indentation hardness value is comparable for both the fine and the coarse fractioned feedstock. In case of the Vickers testing the same effect was established. As the Vickers measurements were performed by a minor experienced operator, the tests were repeated by another more experienced person. For the sample C1 a significant lower value of 1124 HV0.3 with comparable standard deviation values of 68 and 79, respectively, were derived. In a further series on the same sample the standard deviation could be reduced significantly to 27 for both 5 and 10 measurements by excluding nonuniformly shaped indentation pits showing different lengths of the two diagonals. The mean value of $1152 \mathrm{HV} 0.3$ seems to be the most reliable 
one. When increasing the loading force to $0.5 \mathrm{kp}$, the standard deviation is comparable low with 24 to 27 . But the calculated mean value of 1327 HV0.5 is considerably higher than all values derived with $0.3 \mathrm{kp}$ loading force. Nevertheless the comparison with other testing series showing less dense microstructures resulted in the conclusion, that the standard deviation of Vickers measurements is lowest with $0.3 \mathrm{kp}$ loading force. When applying 0.1 $\mathrm{kp}$, the indentation pits are too small to be analysed correctly, and the standard deviation rises againg. With the higher force of 0.5 increased cracking occurs due to not optimal cohesion of the coatings. Therefore it is the best solution to choose $0.3 \mathrm{kp}$ loading force to obtain results of high reproducibility.

To investigate the necessary number of measurement repetitions in correlation to the porosity as weakening effect of the coatings cohesion, samples with extraordinary high and relative low porosity were measured 50 times with all techniques. The relative uncertainty of the derived mean value is plotted over the number of repetitions (see Figure 5). It is calculated as follows:

Calculation of standard deviation: $s=\sqrt{\frac{\sum_{i=1}^{n}\left(x_{\text {mean }}-x_{i}\right)}{n-1}}$

Calculation of mean standard deviation: $S_{\text {mean }}=\frac{s}{\sqrt{n}}$

$$
\text { Calculation of relative uncertainty: } \varepsilon=\frac{S_{\text {mean }}}{x_{\text {mean }}}
$$
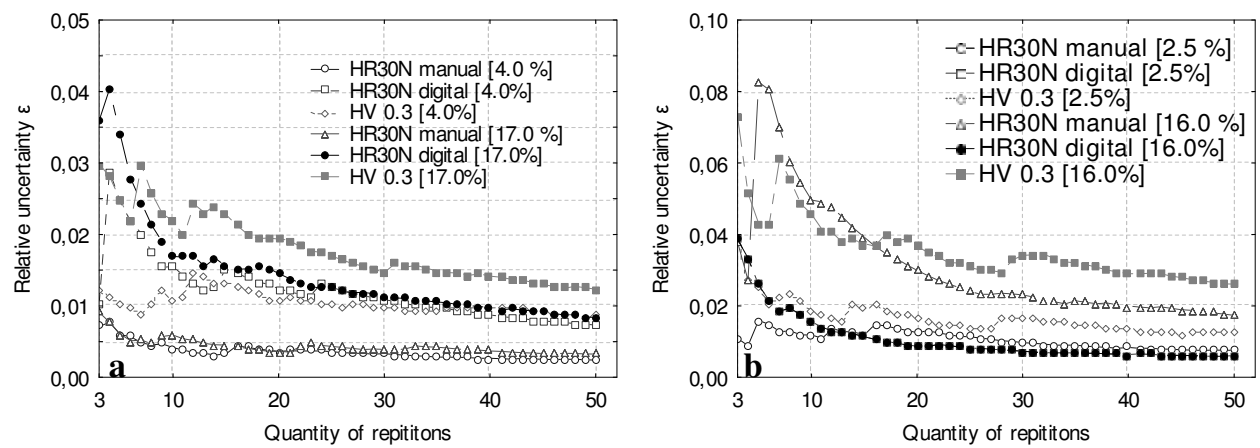

Fig. 5. Relative uncertainty of indentation hardness values for chromia (a) and $\mathrm{Cr}_{3} \mathrm{C}_{2}-\mathrm{NiCr}$ (b) coatings in relation to the measurement technique, the quantity of measuring repetitions and the coatings porosity given in brackets

As expected the relative uncertainty of the derived mean hardness value is significantly higher for the samples with high porosity compared to the more dense coatings. The values tend to remain static when more than approximately 20 repetitions are made, whereas this trend is reached after circa the half quantity of measurements when testing the denser 
coatings. Furthermore not the same degree of certainty can be reached when testing coatings with the high porosity. In further workings this tool will be investigated to work out a measuring concept to classify the reliability of indentation hardness testing of thermal sprayed coatings.

\subsection{Corrosion and wear behaviour}

The corrosion resistance of the coatings was determined with salt spray tests according to DIN EN ISO standard 9227. For this purpose mild and stainless steel substrates were coated and were exposed for 240 hours to a corroding atmosphere produced by spraying a sodium chloride solution. The appearance of corrosion products was evaluated every 24 hours. In addition the samples were weighed before and after the test period to determine mass increasing effects caused by formation of corrosion products. During the testing period the mass of the samples increased because of the formation of corrosion products, Table 2 . In the case of the carbide based coatings the use of the fine fractionated feedstock lead to a considerable improvement in terms of corrosion resistance, the samples sprayed with fine powders showed significant less mass increases than the standard fractionated samples. The $\mathrm{Cr}_{2} \mathrm{O}_{3}$ coatings showed a quite contrary behaviour. This is due to the fact, that the chromia coatings received no sealing treatment leaving, so that the salt media could reach the substrate through the thin coating more easily compared to the thicker conventional sample. The coatings on stainless steel substrates showed the same behaviour like the coatings on mild steel substrates. But of course the actual values were lower due to the higher corrosion resistance of stainless steel.

\begin{tabular}{|l|c|c|}
\hline Coating system & Feedstock grain size/ Sample & $\begin{array}{c}\text { Mass increase on substrate } \\
\mathbf{1 . 0 0 3 7 / 1 . 4 3 0 1 ~ [ ~ m g ] ~}\end{array}$ \\
\hline $\mathbf{C r}_{\mathbf{2}} \mathbf{O}_{\mathbf{3}}$ & $-25+5 \mu \mathrm{m}(\mathrm{F} 1)$ & $90 / 8$ \\
\hline & $-45+5 \mu \mathrm{m}(\mathrm{C} 1)$ & $38 / 5$ \\
\hline $\mathrm{Cr}_{3} \mathbf{C}_{2}-\mathbf{N i C r}$ & $-15+5 \mu \mathrm{m}(\mathrm{F} 2)$ & $19 / 16$ \\
\hline & $-20+45 \mu \mathrm{m}(\mathrm{C} 2)$ & $111 / 23$ \\
\hline $\mathbf{W C}-\mathbf{C o C r}$ & $-15+5 \mu \mathrm{m}(\mathrm{F} 3)$ & $36 / 8$ \\
\hline & $-20+45 \mu \mathrm{m}(\mathrm{C} 3)$ & $233 / 22$
\end{tabular}

Table 2. Results of the corrosion tests: mass increase of coated samples exposed $240 \mathrm{~h}$ in salt spray fog.

The wear resistance of the coatings was evaluated by ball-on-disk wear tests according to ASTM standard G 99. The ball-on-disk test is a model test for determining friction and wear of two solid surfaces being in sliding contact (ball against coated disk). A sintered WC6Co ball (10 $\mathrm{mm}$ in diameter) fixed into a steady ball holder was pressed against the coated and polished sample disk (105 mm in diameter) with a normal load of $40 \mathrm{~N}$. The disk rotated 2500 cycles with a linear speed of $0.1 \mathrm{~m} / \mathrm{s}$. After the experiments the wear track was examined by microscopic analysis in order to determine the wear volume loss. 
The results of the wear tests after 2500 cycles showed different results for each spray feedstock material. The $\mathrm{Cr}_{2} \mathrm{O}_{3}$ coatings regardless whether based on fine or standard powder fractions showed almost no volume loss. According to optical micrographs of the wear scars a tribofilm was formed consisting of plastically deformed debris and splats. This tribofilm was smoother than the original surface and was placed slightly above the mean line of the unworn surface protecting the surface from further wear, see Figure 6a. During the experiments of $\mathrm{Cr}_{3} \mathrm{C}_{2}-\mathrm{NiCr}$ samples measurable wear scars were formed, Figure $6 \mathbf{b}$. The volume loss was higher on the coating based on the fine powder $\left(0.33 \mathrm{~mm}^{3}\right)$ whereas the wear rate of the standard sample was a bit lower $\left(0.24 \mathrm{~mm}^{3}\right)$. Apparently the above-mentioned phase changes which occurred while processing the fine $\mathrm{Cr}_{3} \mathrm{C}_{2}-\mathrm{NiCr}$ powder influenced the wear behaviour negatively. On the contrary the WC-CoCr coatings regardless whether based on fine or standard powder fractions did not suffer a measurable volume loss. In fact the sintered WC6Co ball was abraded instead of the coatings. This is probably due to the surface finish of the coatings as fine and carbide rich hard grooves (see Figure 3c) abraded the Co-matrix of the ball.
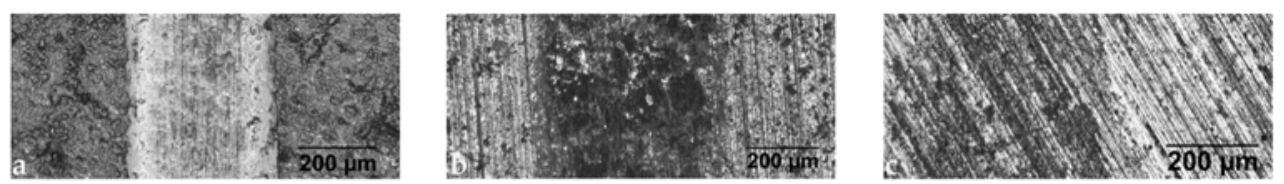

a) $\mathrm{Cr}_{2} \mathrm{O}_{3}$ validation sample (E1)

b) $\mathrm{Cr}_{3} \mathrm{C}_{2}-\mathrm{NiCr}$ validation sample (E2)

c) WCCoCr validation sample (E3)

Fig. 6. Optical micrographs of wear scars after 2500 cycles in ball on disk-tests

\subsection{Conclusion}

Fine $\mathrm{Cr}_{2} \mathrm{O}_{3}, \mathrm{Cr}_{3} \mathrm{C}_{2}-\mathrm{NiCr}$, and WC-CoCr feedstock with grain sizes below $25 \mu \mathrm{m}$ were processed in order to investigate the spraying of near net shape coatings. The characteristics of the coatings based on fine powders were analysed and compared to standard coatings based on $-45+5 / 20 \mu \mathrm{m}$ powder fractions. Compared to standard coatings it was possible to improve the key coating characteristics porosity, surface roughness and corrosion resistance significantly. Other coating properties like hardness or wear resistance showed comparable behaviour as that of standard samples. In case of spraying cermet feedstock, especially $\mathrm{Cr}_{3} \mathrm{C}_{2}-\mathrm{NiCr}$, optimized parameter sets are necessary to control decarburization and oxidation.

\section{Design and optimization}

Thermal Spraying is an indirect process, where only the basic conditions can be controlled by altering the process parameters. A deterministic control of the transfer of heat and kinetic energy to the feedstock particle is not possible. Due to the vast variety of process parameters some time said to be more than one hundred (Lugscheider \& Bach, 2002) - sophisticated approaches of designed experiments are a good tool to both understand the complex interdependencies between the parameters and to optimize coatings properties due to the demands. In the following the basic considerations and the proof of suitability of statistical design of experiments are given for controlling and optimization of thermal spraying processes. 


\subsection{Basic considerations}

The goal of conducting experiments is to get information about the functional relation between the process conditions and the resulting coatings properties determining both the economical effectiveness of the coating process as well as the coatings behaviour under operational conditions. For example the deposition efficiency (DE) of the feedstock material in case of plasma spraying of oxide ceramics, i.e. the percentage of the inset feedstock contributing to the coating buildup, is dependent of the chosen federate as well as the achievable heat transfer from the plasma to the feedstock particles. Therefore it can be assumed, that there is a functional correlation between the powder feedrate, the applied amperage to the plasma and the chosen plasma and secondary gas mixture (species, total flow and ratio) controlling the specific heat and therefore the capacity of heat transfer of the plasma. Two further parameters defined by the inset feedstock are its heat of fusion and median grain size as the heat is transferred from its surface into its volume. The spraying distance is parameter controlling the time of flight of the particles in the plasma and therefore the time of exposure to heat, but there is a strong interdependency with the applied amperage. The higher the amperage, the higher is the temperature and heat capacity of the plasma, but also its velocity and therefore the time of flight for the particles decreases with raising the amperage. All together the functional dependency of the DE can be stated as follows:

$$
\mathrm{DE}=\mathrm{f}_{(\text {amperage, plasma gases, spraying distance, particle size, } \ldots \text { ) }}
$$

or in other terms:

$$
y D E=f(x 1, x 2, \ldots, x n)
$$

One approach to derive information about the correlation of the coating's criteria DE with the parameters is to vary the process parameters one by one in every single spraying experiment holding two complications: The number of experiments is large and the interdependency between distinct parameters cannot be estimated. Therefore the use of statistically designed experiments is a good alternative, as both goals can be realized utilizing this tools (for an example see Heimann, 2008). The experiments are arranged in matrices with a deterministic alteration of the factors (i.e. parameters to be investigated) on distinct levels. Afterwards the coatings criteria are measured and the results are analysed regarding the factorial effects (i.e. the correlation with the parameters). The ways to obtain the correlation can be divided into factorial analysis by means of multiple regressions on the one hand and by analysing the variance of the measured results according to the variation of process parameters (ANOVA) methods. The usability of the second approach in the field of thermal spraying is shown in the following using the examples of the experimental series described in chapter 2. For a comprehensive overview of the methods including model testing etc. see (Dean \& Voss, 1999; Mason, 2003; National Institute of Standards and Technology [NIST], 2011).

\subsection{Robust quality control basing on ANOVA techniques}

The variability of thermal spray processes regarding coatings characterics and quality is a well-known problem in application. In the field of the designing and development of feedstock and coating systems designed experiments are sophisticated tools to achieve 
sufficient coating qualities in specified tolerance regions. Besides the gathering of the relevant know-how regarding the spraying of certain feedstock etc., the processes must be insensitive against deviations over longer periods of time to reach this goal. For example, in Figure 7 a quadratic functional correlation between the deposition efficiency of feedstock and the applied amperage in the APS process is assumed.

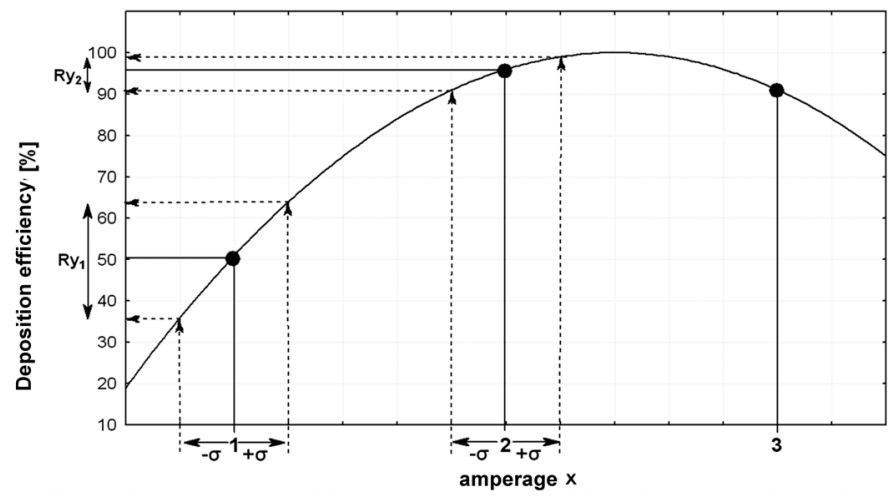

Fig. 7. Assumed correlation between applied amperage and relative deposition efficiency

The sketch shows, that the same magnitude of deviation of the applied amperage from the chosen control value results in two different deviation spans of the resulting $D E\left(R_{\mathrm{y} 1}\right.$ and $\mathrm{R}_{\mathrm{y} 2}$ ). Another point is the influence of noise factors, which also can disturb the known relation between process parameters and the expected result. Following the approach after G. Taguchi, the effects of the control factors (i.e. process parameters) are extended by the effects of noise and signal factors (see Figure 8).

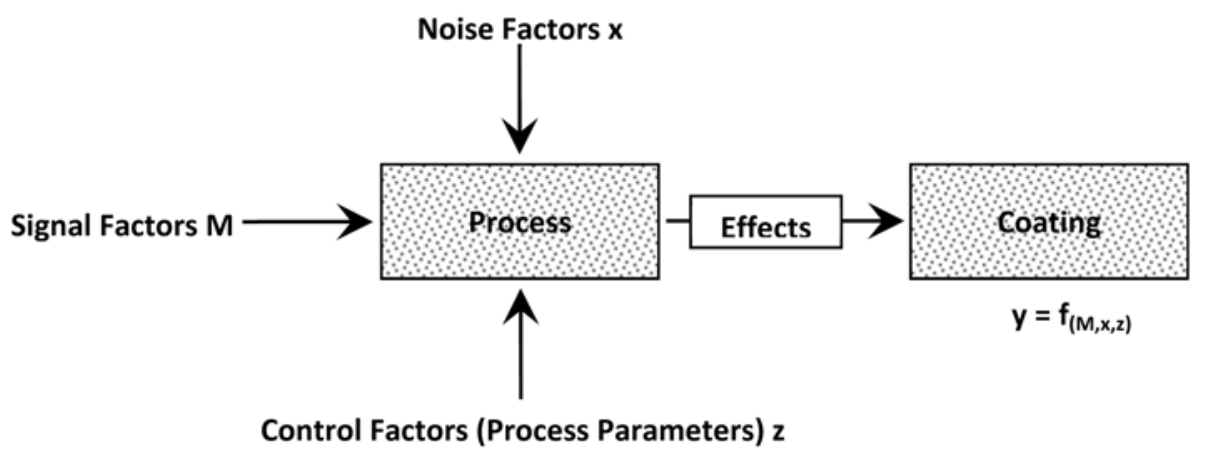

Fig. 8. Scheme of the effects of control, noise and signal factors on the coating process (after Phadke, 1989)

The basic tools of the method are the so called orthogonal arrays. Like the conventional matrices of designing experiments for factorial designs, the levels of the parameters to be investigated are arranged by given plans. But unlike the methods of DoE, the functional correlation between factors and the measured results are expressed in terms of a signal-to- 
noise ratio. The goal of the method is not to optimize one response regardless of other coatings criteria, but to achieve results being robust against the effect of noise factors like e.g. the wear of parts like the electrodes of the plasma gun etc. The signal factors also show effects on the results, but are kept normally constant, like e.g. the traverse speed of the gun relative to the substrate. In the following the results of applying the method are discussed.

\subsection{Applying orthogonal arrays for optimizing coatings}

Taguchi techniques were utilized in order to reduce the number of experiments and to evaluate and to adjust main process variables. The effectiveness of these techniques could be verified by spraying validation samples successfully. A Taguchi experimental design was used to reduce the number of coating experiments. Four main process variables, or factors, were identified and varied on three levels in an $\mathrm{L}_{9}$ orthogonal array. This matrix dictated the combination of levels, at which the factors should be set for each experiment, Table 3 . Furthermore the process output variables, or responses, which should be optimized, were defined. For near net shape coatings a surface roughness being as low as possible is requested. So the aim of the experiments was to obtain a set of spray parameters for each material, which allows the spraying of coatings with low surface roughness under consideration of cost-effective deposition rates. It was also tried to improve coating properties like hardness and porosity. The results were analysed by means of ANOVA to determine the relative contributions of the various main factors and interactions among them. This allowed a prediction for an optimal parameter set for each investigated spraying feedstock.

\begin{tabular}{|l|c|c|c|c|}
$\begin{array}{l}\text { Factor } \Rightarrow \\
\text { Experiment } \\
\text { No. } \downarrow\end{array}$ & Particle size & $\begin{array}{c}\text { Current (APS)/ } \\
\text { Air-Fuel-Ratio } \\
\text { (HVOF) }\end{array}$ & $\begin{array}{c}\text { Spray } \\
\text { distance }\end{array}$ & Powder carrier gas \\
\hline $\mathbf{1}$ & 1 & 1 & 1 & 1 \\
\hline $\mathbf{2}$ & 1 & 2 & 2 & 2 \\
\hline $\mathbf{3}$ & 1 & 3 & 3 & 3 \\
\hline $\mathbf{4}$ & 2 & 1 & 2 & 3 \\
\hline $\mathbf{5}$ & 2 & 2 & 3 & 1 \\
\hline $\mathbf{6}$ & 2 & 3 & 1 & 2 \\
\hline $\mathbf{7}$ & 3 & 1 & 3 & 2 \\
\hline $\mathbf{8}$ & 3 & 2 & 1 & 3 \\
\hline $\mathbf{9}$ & 3 & 3 & 2 & 1 \\
\hline
\end{tabular}

Table 3. Matrix used for the Taguchi experimental designs

For validation samples were coated using the predicted optimum spray parameters shown in Table 4, the results are shown in Table 5. The values predicted and actually measured proved to be quite consistent. It can be reasoned that the validation experiments were able to confirm and to reproduce the predicted values.

While comparing validation and standard samples the latter showed higher deposition rates. Of course this has to be ascribed mainly to the fact that coarser spraying feedstock were used to spray the standard samples. The validation samples showed significant lower 
surface roughness. Especially the carbide based coatings showed low $R_{a}$ values (about $2.7 \mu \mathrm{m}$ ) compared to the $R_{a}$ values of the standard samples (near $7 \mu \mathrm{m}$ ). The hardness of the coatings did not vary much regardless of which powder fraction was processed.
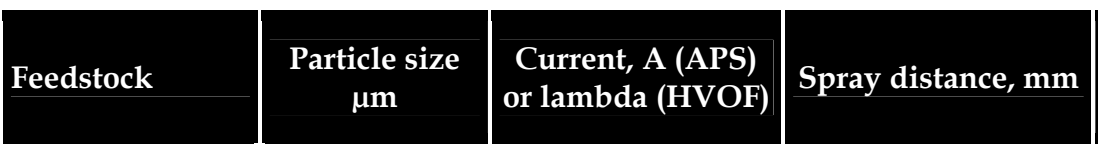

\section{Powder \\ carrier gas, slpm}

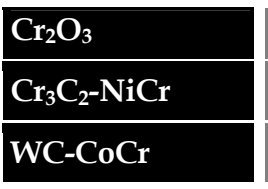

\begin{tabular}{|l|}
\hline$+25-5(3)$ \\
\hline$+15-5(1)$ \\
$+15-5(1)$ \\
\hline
\end{tabular}

\begin{tabular}{|l|}
\hline $650(3)$ \\
\hline $1.4(1)$ \\
$1.4(2)$ \\
\hline
\end{tabular}

\begin{tabular}{|l|}
\hline $100(2)$ \\
\hline $270(1)$ \\
\hline $310(2)$ \\
\hline
\end{tabular}

Table 4. Predicted optimum spray parameters (the numbers in brackets show the corresponding parameter level)

\begin{tabular}{|l|c|c|c|c|}
\hline Feedstock & Sample & $\begin{array}{c}\text { Deposition rate, } \\
\boldsymbol{\mu m} \text { per pass }\end{array}$ & $\begin{array}{c}\text { Surface roughness } \\
\mathbf{R a}, \boldsymbol{\mu m}\end{array}$ & $\begin{array}{c}\text { Hardness } \\
\text { HR 15 N }\end{array}$ \\
\hline $\mathbf{C r}_{\mathbf{2}} \mathbf{O}_{\mathbf{3}}$ & Predicted & 18.4 & 3.2 & 87 \\
\hline & Measured & 18.7 & 2.5 & 89 \\
\hline & Standard & 16.9 & 4.5 & 87 \\
\hline $\mathbf{C r}_{\mathbf{3}} \mathbf{C}_{\mathbf{2}}-\mathbf{N i C r}$ & Predicted & 3.6 & 2.8 & 73 \\
\hline & Measured & 3.3 & 2.7 & 77 \\
\hline & Standard & 23.9 & 6.7 & 76 \\
\hline $\mathbf{W C - C o C r}$ & Predicted & 11.8 & 3.1 & 89 \\
\hline & Measured & 11.3 & 2.7 & 87 \\
\hline & Standard & 26.9 & 6.8 & 88 \\
\hline
\end{tabular}

Table 5. Predicted and measured results obtained from validation and standard samples

It can be summarized, that by applying the method of signal-to-noise ratios derived from the evaluation of orthogonal arrays, the workings could be reduced to nine experiments while investigating the effects of four quantitative parameters on three levels. The results show, that by applying this technique, reproducible forecasts regarding the optimisation of thermal spray coatings can be derived.

\section{Developments of new applications}

As stated at the beginning there is the goal to make use of finer grain sizes of feedstock powders to reach denser coatings showing higher cohesion and adherence to the substrate. The lower limit of feeding powders into the process is in the one-digit micrometer range. By dispersing of the feedstock in a liquid outer phase or the formulation of feedstock direct in a suspension by chemical methods, use can be made of nanometer sized feedstock. In the following the efforts are shown in new results regarding the achievement of coatings, which could not be realized by means of thermal spraying before. 


\subsection{Suspension plasma spraying of triboactive coatings}

Up to now no coating systems are marketable in the field of metal forming like the direct hot extrusion process, which provide both surface protection of the parts being in contact to the billet (i.e. container and die), and a significant reduction of the frictional losses being induced by the billet passing along the container walls. To dispense the use of lubricants and to enhance the usable forming capacity of the process, different oxide ceramics were given in one suspension and plasma sprayed. The aim is to reach a mixing of the feedstock to obtain deterministic solid solutions of the oxide phases which show a reduction of their coefficient of friction under dry sliding conditions. To reach this goal the high surface-tovolume ratio of feedstock with primary particle sizes below $100 \mathrm{~nm}$ was used. By means of $x$-ray diffraction it could be proven, that the desired phases could be synthesized. The coatings showed a considerable lowering of their frictional coefficient in tribological testing against steel $100 \mathrm{Cr} 6$ in the region of the operation temperatures for the hot extrusion of aluminium alloys. Besides the experimental work the fundamentals of the mixing process of different oxides regarding crystallographic aspects are discussed.

Thermal sprayed coatings are not commonly used in the field of massive forming due to the high demands concerning the cohesion and adhesion of tool coatings. The cause is adhesive wear being induced by the elevated temperatures of operation and high relative velocities between the work piece and toolings resulting in high tensile and shear stresses. Nevertheless, there is the challenge to establish coatings to reduce both the wear of tools and frictional losses in the processes. For example in the case of direct hot extrusion, up to $60 \%$

of the forming force have to be applied to counterbalance frictional losses. To come up against that losses different lubricants and material separating agents are used, but with the disadvantages of a higher degree of reworking of the semifinished extruded product and a limited thermal stability of the substances. To overcome these disadvantages, the usability of specific oxide ceramic phases basing on titania was tested, which show a reduction of their frictional coefficient under tribological operation and elevated temperatures. The desired phases should be synthesized in the suspension plasma spraying process by mixing different oxide feedstock with titania in one suspension.

\subsubsection{Crystallographic aspects}

In the system Titanium-Oxygen different non stoichiometric phases are known, which show the ability for deformation under mechanical stress due to a shearing of crystal lattice planes. These phases show a reduction of the frictional coefficient in dry sliding conditions under elevated temperatures of some 100 degrees Celsius. The beneficial effect was linked to the shearing processes being temperature induced (Gardos, 1988), the fundamental mechanism of the shearing processes are discussed elsewhere (Anderson, S. and Tilley, R. J. D., 1972). As the phases are expected to be not thermodynamically stable (for a discussion of redistribution effects of titanium and oxygen see Wood, G. J. et al., 1982), another approach was intended for these workings. By addition of a second cation besides $\mathrm{Ti}^{4+}$, phases can be obtained which are homologues to the nonstoichiometric titaniumoxides. Those so called Andersson-phases were first described for the system Ti-Cr-O (Andersson, S., Sundholm, A. \& Magnéli, A., 1959) showing a composition of $\mathrm{Ti}_{\mathrm{n}-2} \mathrm{Cr}_{2} \mathrm{O}_{2 \mathrm{n}-1}$. 
As chromium exhibits a high steam pressure with rising temperature and therefore may tend to evaporate out of the lattice, the homovalent substitution of the $\mathrm{Ti}^{4+}{ }^{+}$cation in the rutile base lattice was aspired. Several cations where chosen based on the rules for substitution processes stated by V. M. Goldschmidt (Goldschmidt, V. M., 1926), besides $\mathrm{Cr}^{3+}$ primary $\mathrm{Ni}^{3+}, \mathrm{Co}^{3+}$ and $\mathrm{Zr}^{4+}$ by considering the ionic radii and coordination given in (Shannon, R.D., 1976). The goal is to reach phases with a similar composition compared to the Andersson-type phases on the one hand and a sufficient stability in temperature ranges up to $800^{\circ} \mathrm{C}$ on the other, which are commonly used for hot extrusion of aluminum and copper based alloys.

The assumption that the applicability of substitution processes may lead to the formation of solid solutions of the desired stoichiometry can be proven by means of the Inorganic Crystal Structure Database. In Figure 9 for example the structures of the cubic Co(II)-oxide and of tetragonal rutile (i.e. $\mathrm{Ti}(\mathrm{IV})$-oxide) are shown on top, where the oxygen is represented by the larger balls.

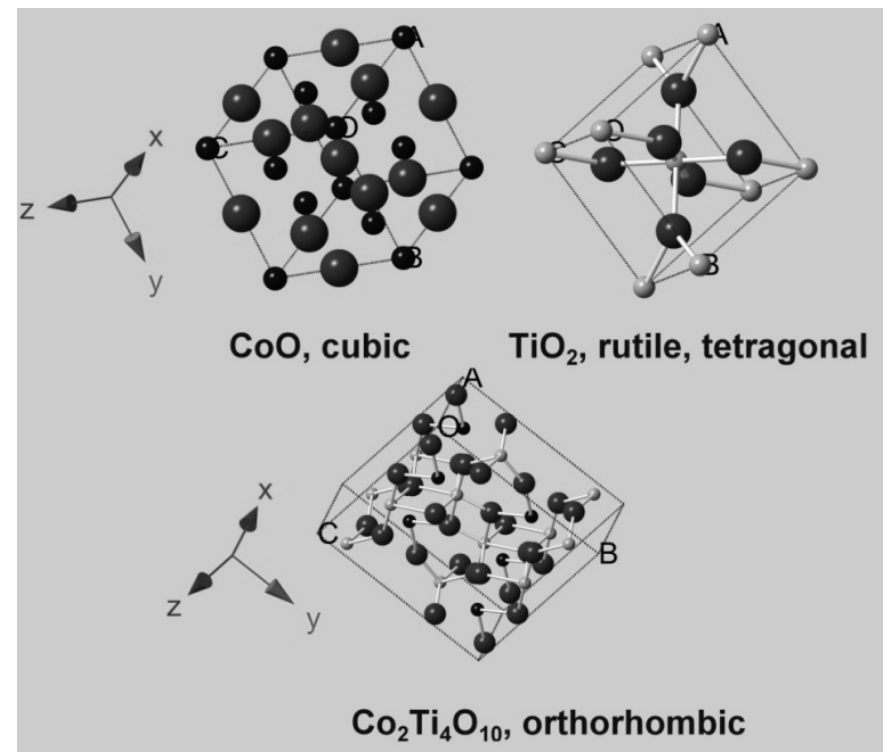

Fig. 9. Structures of Co- and Ti-oxide (top) and of the "mixed" solid solution oxide (bottom)

From the structure it can be inferred, that both cations have similar radii, which is - besides the valence and the coordination by the surrounding ions - the key requirement for the dissolution of the oxides. When both oxides are mixed, a structure of lower symmetry (orthorombic) is formed with a composition of $\mathrm{Co}_{2} \mathrm{Ti}_{4} \mathrm{O}_{10}$. The difference compared to the aspired composition of $\mathrm{Co}_{2} \mathrm{Ti}_{4} \mathrm{O}_{11}$ for $\mathrm{n}=6$ is due to the fact, that the divalent cobalt is incorporated in the structure instead of the trivalent ion. Like the most structures being crystallographic possible solid solution of rutile with the named oxides, the cobalt-titaniumoxide with trivalent Co-ions is not refined yet. Without the feasibility to refine the structures, the full quantitative Rietveld analysis by means of X-ray diffraction of the sprayed coatings is not possible. 


\subsubsection{Results}

\subsubsection{Phase analysis}

Three different mixtures of titania (rutile) with the named oxides of trivalent cobalt, nickel and chrome where sprayed on structural steel SJ235R. X-ray diffraction analysis were performed on the coating systems using copper radiation, the diffraction patterns are plotted in Figure 10 with an offset of 500 counts between the samples. The patterns where checked regarding the presence of unmelted or recrystallized feedstock, the possible solutions as well as reduced oxides and reaction products of the feedstock with the flux melting agent. Because of the marginal coating thickness of some tens of micrometres, the influence of the substrate is recorded in the patterns. As the relative intensity of reflection (RIR) of ferrite is considerably higher than that of the other phases present in the coatings, its peaks are of highest intensity (see the peaks at approximately 45 und $75^{\circ} 2 \theta$ ). Since no

structure data is available for the aspired solid solutions, the reference intensity ratio stated in the ICDD PDF4 database entries where used to perform semi quantitative analysis. As no RIRs are given for the solid solutions in the powder diffraction files, values of phases with nearly identical stoichiometry where assumed. The fractions of ferrite were deducted and the adjusted phase contents of the coatings are given in Table 6.

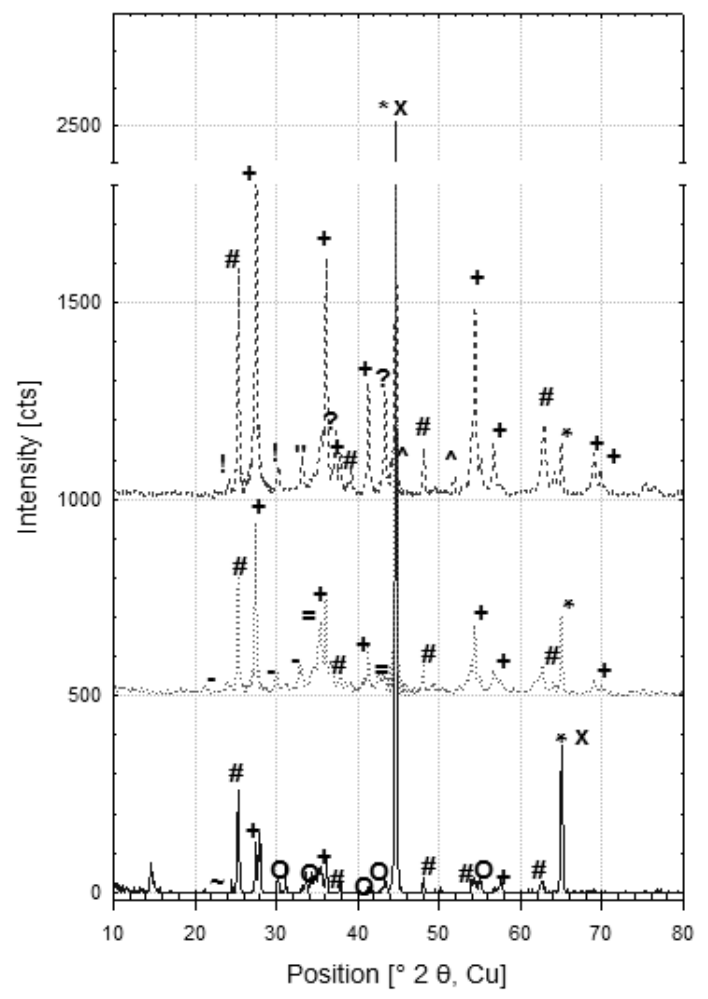

\# Anatase, $\mathrm{TiO}_{2}$

+ Rutile, $\mathrm{TiO}_{2}$

$\sim$ Escolaite, $\mathrm{Cr}_{2} \mathrm{O}_{3}$

x Chrome

O Andersson-Phases

- Cobalt-Titanium-Oxides

$=$ Cobalt Boron Oxide

* Ferrite

! $\mathrm{Ti}_{6} \mathrm{O}_{11}$

" Nickel-Titanium-Oxides

$\wedge$ Nickel

? Bunsenite, NiO

-..- $\mathrm{TiO}_{2} \times \mathrm{Ni}_{2} \mathrm{O}_{3}+1000$ cts

$\mathrm{TiO}_{2} \times \mathrm{Co}_{2} \mathrm{O}_{3}+500$ cts

$-\mathrm{TiO}_{2} \times \mathrm{Cr}_{2} \mathrm{O}_{3}$

Fig. 10. Diffraction patterns of three suspension plasma sprayed coating systems 


\begin{tabular}{|l|c|c|c|c|c|}
\hline & \multicolumn{5}{|c|}{ Phase Contents (atomic percent) } \\
\hline Sample & Ti-Oxides & $\mathrm{Ni}, \mathrm{Co}-\mathrm{Oxides}, \mathrm{Cr}$ & $\mathrm{Ti}-(\mathrm{Ni}, \mathrm{Co}, \mathrm{Cr})$-Oxides & Borates & Traces \\
\hline $\mathrm{TiO}_{2} \times \mathrm{Ni}_{2} \mathrm{O}_{3}$ & 55 & 7 & 26 & 10 & $2 \% \mathrm{Ni}$ \\
\hline $\mathrm{TiO}_{2} \times \mathrm{CO}_{2} \mathrm{O}_{3}$ & 39 & 0 & 29 & 33 & - \\
\hline $\mathrm{TiO}_{2} \times \mathrm{Cr}_{2} \mathrm{O}_{3}$ & 13 & 10 & 75 & 0 & $2 \% \mathrm{Cr}_{2} \mathrm{O}_{3}$ \\
\hline
\end{tabular}

Table 6. Phase contents of the three coating systems

In case of the $\mathrm{Ni}$ - and Co-containing coatings, significant amounts of $\mathrm{Ti}(\mathrm{IV})$-oxides were measured, of which approximately one third is anatase. As stated in (Bolelli, G., et al., 2009), in case of rutile feedstock the phase content of anatase especially in suspension sprayed coatings can be explained by slow cooling due to re-solidification of molten droplets in the process, compared to formation of rutile in rapid quenching on the substrate. Considering this explanation another assumption might be the influence of elevated substrate temperatures in the SPS process leading to a more slowly cooling of molten titania particles after impinging on the substrate. To distinguish both possible mechanisms further investigations will be conducted considering the thermodynamics of the phase changes of both titania species. In the case that the anatase content correlates well with the content of re-solidificated particles in the coating, the anatase-to-rutile ratio can be used to optimize the injection and spraying parameters.

For the coatings containing nickel, about $7 \%$ percent of $\mathrm{Ni}(\mathrm{II})$-oxide were found, whereas in titania-cobalt-oxide systems no remains of the Co-feedstock was detected. The employed trivalent oxides of both cations decompose towards the divalent oxide at temperatures above approximately $600^{\circ}$ in case of the $\mathrm{Ni}$-oxide and $1910^{\circ} \mathrm{C}$ for the $\mathrm{Co}_{2} \mathrm{O}_{3}$. Otherwise the contents of borates formed by reactions of the boron oxide with the feedstock oxides is three times higher for the Co-based system compared to the titania-nickel-oxide coating. As the absolute value of the enthalpy of formation of the cobalt-borate is higher than that of the Niborate (Hawk, D. and Müller, F.; 1980; Paul, A., 1975), the Co-oxide feedstock is diluted in the boron oxide to a much higher extent compared to the Ni-containing system, and no remaining $\mathrm{Co}_{2} \mathrm{O}_{3}$ is embedded in the coating. In contrary to that the contents of Ni-borates are small in the titania-Ni-oxide coating, and remains of the $\mathrm{Ni}$ (II)-oxide are recorded. The phase contents of the aspired solid solutions are below $30 \%$ for both coatings systems.

Compared to the Ni- and Co-containing coatings the mixing of titania with chromia leeds to different phase compositions. Due to the marginal miscibility of chromia with boron oxide (Tombs, N. C.; Croft, W. J. \& Mattraw, H. C.; 1963), no borates and also just small amounts of the feedstock powders are found. The Andersson-phases with the mentioned stoichiometry of $\mathrm{Ti}_{\mathrm{n}-2} \mathrm{Cr}_{2} \mathrm{O}_{2 \mathrm{n}-1}$ amount to three quarters of the total coatings composition. Therefore it can be concluded, that the degree of mixing of the feedstock is significantly higher for the titania-chromia system. If the melted phase of the boron oxide supports the mixture process of the both oxide ceramics without further reaction cannot be clarified. Possibly the heat of the process is better transferred to the coarser feedstock of approximatly $100 \mathrm{~nm}$ median crystallite size compared to 30 to $60 \mathrm{~nm}$ of the feedstock of the Ni- and Cocontaining coatings. As the heat transfer degreases drastically when the agglomerate size of the feedstock particles falls below a critical limit (so called Knudsen effect, Fauchais, P. et al., 2008), this might be a supposable explanation of the higher degree of feedstock mixing in the case of the titania-chromia system. 
In addition, with approximately $10 \%$ significant amounts of chromium are present in the coatings, being formed by reduction of the chromia feedstock. This effect is only detected when spraying the suspension with the Triplex-II and not when using the DELTA-Gun, and further on when besides chromia titania is present in the suspension. This result is probably due to the large gap between the absolute values of the Gibbs free energy of the two oxides. Hence the chromia is reduced in the presence of titania. By means of visible spectroscopy protons where found supposedly originating from the vaporization of the water of the suspension, but no ions of oxygen where detected. Together with the lamellar flow of the plasma jet of the Triplex resulting in marginal entrainment of surrounding air, apparently the conditions are given for the reduction of the chromia towards chrome.

\subsubsection{Tribological testing of Andersson type coatings}

Since the contents of the solid solutions of titania with another oxide were the highest in case for the titania-chromia system, tribological testing for recording the coefficient of friction dependent on the temperature of operation were conducted with coatings of this Andersson type phases using a ball on disk configuration. The coatings rotated against a ball of 100Cr6 $(1.3505$, diameter $=5 \mathrm{~mm})$ with $0.1 \mathrm{~m} / \mathrm{s}$, the loading force was $5 \mathrm{~N}$. The coefficient of friction was recorded in three runs on different samples at room temperature, $600^{\circ}$ and $800^{\circ} \mathrm{C}$ (see Figure 11).

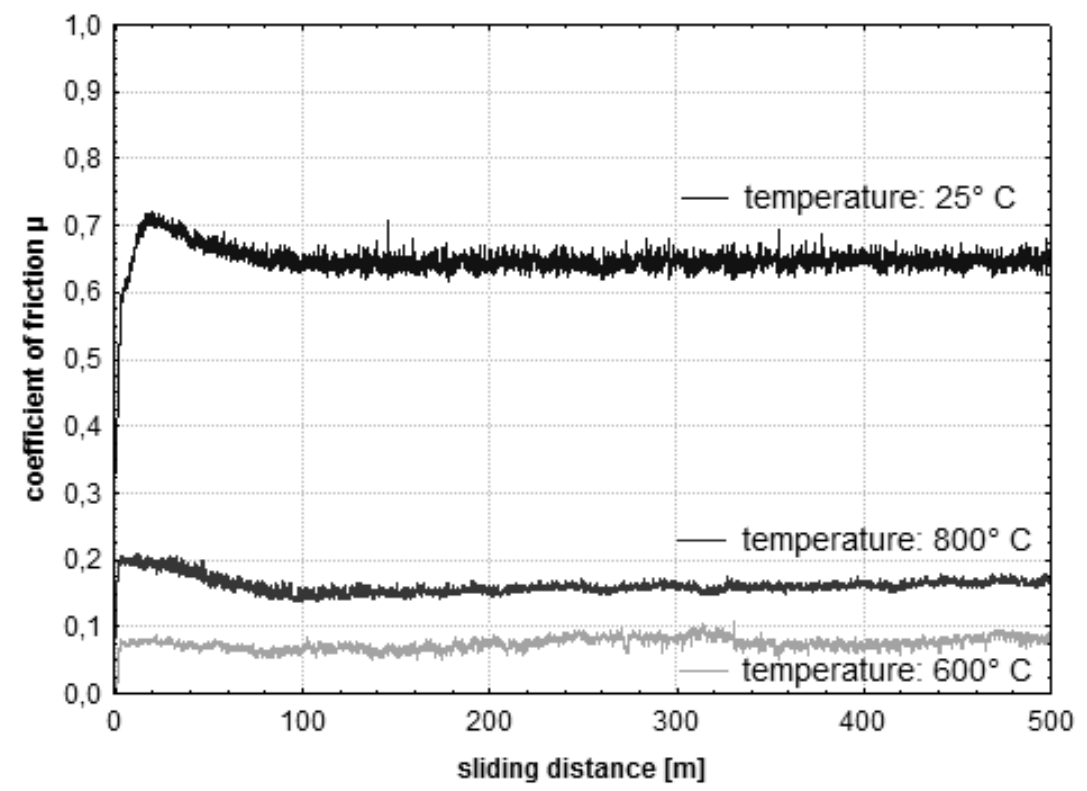

Fig. 11. COF of Andersson type coating systems measured against $100 \mathrm{Cr} 6$ at $\mathrm{RT}, 600^{\circ}$ and $800^{\circ} \mathrm{C}$

The friction pairing shows a COF of more than 0.6 when running at room temperature. When rising the temperatures up to $600^{\circ} \mathrm{C}$, the ratio of the frictional force to loading force drops considerably to below 0.1 . On the one hand this effect is surely due to the softening of 
the ball (see the debris of the ball on the coating in the second picture from top on the left hand in Figure 12), but this effect is desired as the billet in the extrusion process shows a comparable behavior. For this reason, the testing of the coatings in tribometer experiments is not directly comparable to the hot extrusion process, as the soft consistency of the flowing billet above yield stress cannot be tested because the ball would be abraded promptly and its holder would scratch the coating. But compared to the given values of operating unlubricated containers of more than 0.2 (Bauser, M.; Sauer, G. and Siegert, K., 2006), a significant lower frictional force was measured. Besides the tribological activity of the coating it shows good material separating properties against $100 \mathrm{Cr} 6$. When rising the temperatures to $800^{\circ} \mathrm{C}$, the $\mathrm{COF}$ rises again to values of nearly 0.2 . An explanation is the formation of black ferrous oxide (supposable magnetite) instead of the red oxide (presumably haematite), showing higher hardness and unfavourable tribolological properties (Barbezat, G., 2006).

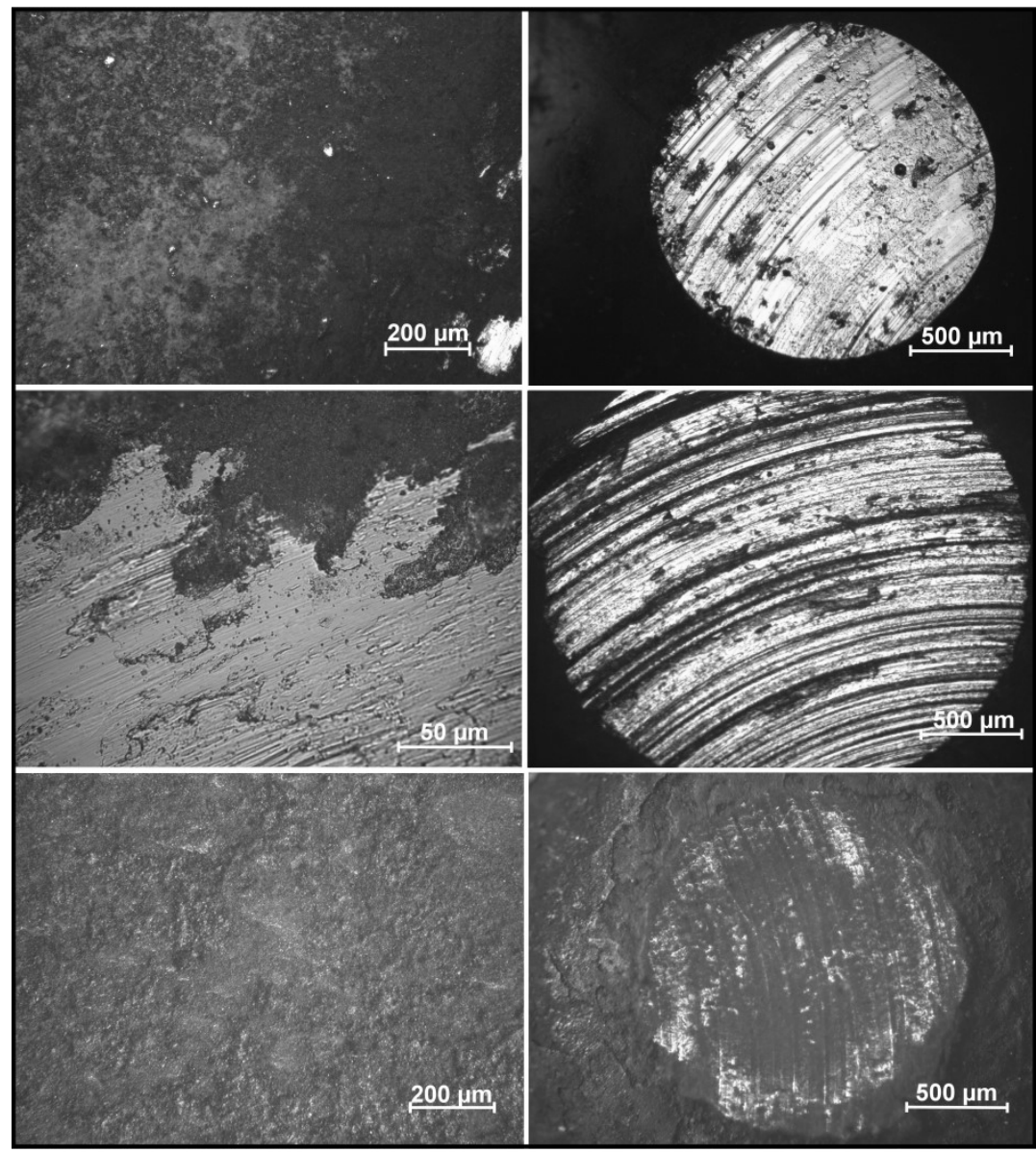

Fig. 12. Top views of the scare tracks left and corresponding friction surfaces of the counterparts from room temperature (top) to $800^{\circ} \mathrm{C}$ (bottom) 
This finding is another example for the low comparability between tribometer experiment and hot extrusion, as the billet is pressed under air exclusion in the container. Another guess is a lack in thermal stability of the Andersson phases. Other SPS coatings sprayed with the same feedstock composition where tempered at different temperatures $\left(300,500\right.$ and $\left.800^{\circ} \mathrm{C}\right)$ for several hours. The colouring of the coatings changed with temperature (see top views on the left hand side of Figure 13), as the phase composition changes (see the corresponding diffraction patterns on the right). The marked peaks in the diffraction pattern of the sample tempered at $500^{\circ} \mathrm{C}$ are caused by the Andersson phases. As clearly can be seen, this peaks are significantly smaller in the sample being not tempered and that one tempered at $800^{\circ} \mathrm{C}$. So it can be stated, that the tribological active phases can be formed with rising temperature within the coatings during operation, but also may decompose with further increased temperatures.
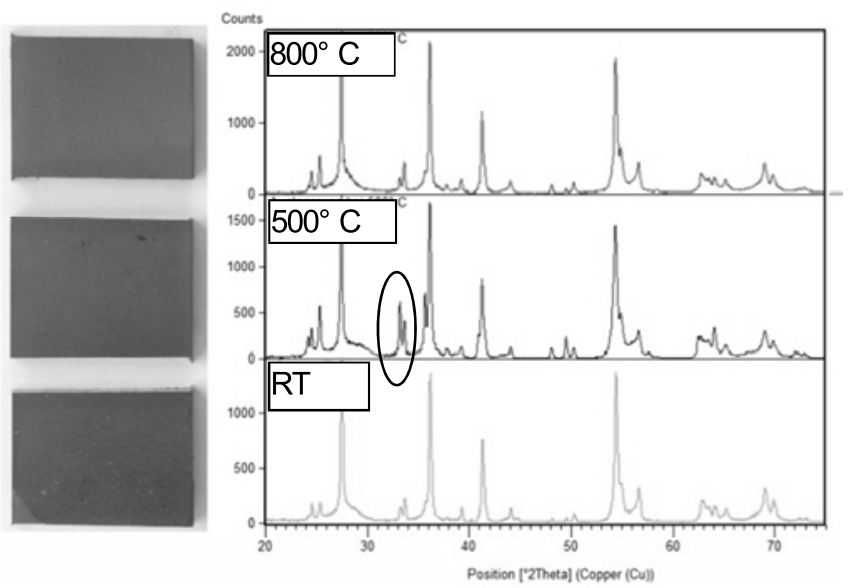

Fig. 13. Alteration of the phase composition of Andersson type coatings in relation to temperature (right side) and corresponding top views of the tempered samples

\subsubsection{Conclusion}

By means of x-ray diffraction analysis it could be proven, that the mixing of titania and other oxide feedstock in the SPS process could be realized. For example the achieved Andersson type coating system sprayed with titania and chromia containing suspensions showed a temperature induced lowering of their coefficient of friction when rotated against 100Cr6. Further experiments will be conducted to better understand the parameters controlling the mixing process of the feedstock on one hand and regarding tribological experiments using aluminium and copper based extrusion alloys.

\subsection{Comparison of multielectrode plasma guns for development of new coatings}

When high throughput is intended, three cathode guns are a supposable solution. Due to their stationary plasma jet and elevated power characteristics, higher feeding rates concurrent with sufficient deposition efficiencies can be realized compared to one-cathode plasma guns. On the contrary to those well-known equipments a newly marketable system 
makes use of three anodes to combine high power inputs into the plasma as well as stable process conditions. Besides a more narrow nozzle outlet diameter compared to multicathode designs hydrogen can be used as secondary plasma gas, both resulting in higher plasma velocities and net powers. The conceptional designs of two guns are discussed as well as their suitability for suspension and shrouded plasma spraying. The efforts in achieving new plasma sprayed coating systems are presented.

\subsubsection{Design of marketable multielectrode plasma guns}

To overcome the disadvantages of conventional plasma guns especialy regarding the discontinuity of the free jet due to plasma arc root rotation, mulitelectrode guns were developed. Since more than ten years guns basing on the three-cathode-design guarantee high plasma net powers combined with stable feedstock injection conditions. Until now the guns have two disadvantages concerning the use of expensive helium as secondary gas accompanied by low plasma arc voltages on the one hand and the restriction of the minimal nozzle outlet diameter on the other. For example three single plasma fingers originate from the single cathodes being passed through a cascaded neutrode in case of the second generation of the Triplex-design (Sulzer Metco AG, Wohlen/Switzerland). Hence a minimal nozzle outlet diameter of the anode of $9 \mathrm{~mm}$ can be realized because of the thermal design of the gun. Another approach is the inverted design of a plasmatron, where one arc originates from a single cathode and is divided on three anodes after passing the cascade. Therefore for the DELTA-Gun (GTV GmbH, Luckenbach/Germany) a minimal nozzle outlet diameter of $7 \mathrm{~mm}$ can be achieved resulting in higher plasma velocities at the nozzle outlet. Furthermore hydrogen can be used as secondary gas and high brut plasma powers of $80 \mathrm{~kW}$ can be applied to the torch.

\subsubsection{Experimental}

The workings concentrated on the investigations, to what extent both gun concepts are appropriate for inert and reactive shrouded plasma spraying as well as the processing of nanoscaled suspensions. Feedstock was used being not commonly applied in plasma spraying to identify the potential of plasma spraying for possibly new applications. For demonstration purposes coating systems of titanium and chromium as well as their nitrides and Indium-Tin-Oxide (ITO) showing electrical conductance were chosen. For the chromium coatings feedstock obtained from GTV GmbH with two different particle size distributions $(-25+5 \mu \mathrm{m}$ and $-45+5 \mu \mathrm{m})$ were investigated. As titanium feedstock a powder of $-45+10 \mu \mathrm{m}$ came into operation, which is manufactured and distributed by TLS Technik Spezialpulver $\mathrm{GmbH}$ (Bitterfeld/Germany). For SPS suspensions containing 5 wt.-\% ITO (ANM PH 15695, Evonik Degussa $\mathrm{GmbH}$, Marl/Germany) and $\mathrm{Al}_{2} \mathrm{O}_{3}$ (Saint Gobain, Weilerswist/Germany) with primary crystallite sizes of some tens for the first and approximately $150 \mathrm{~nm}$ for the latter were used.

\subsubsection{Results}

\subsubsection{Shrouded plasma spraying}

For both guns modules have been designed and machined to apply shroud gases around the plasma free jet (for details see Figure 14 on the following page). The attachments consist of water-cooled bodies, in which the shrouding gas is injected helically to ensure a sufficient 
shielding against the surrounding air after exiting the shroud. The feedstock injection is realized over middle sections between the exit of the gun nozzle and the shroud gas inlet to avoid interferences with the shroud gas flow. The body housings of the shrouds are integrated in the cooling circuit of the spraying equipment.

The spraying experiments were conducted applying plasma brut powers of approximately 25 to $50 \mathrm{~kW}$ (see Table 7 for spraying parameters). When operating the Triplex high helium flows of 20 SLPM were used to guarantee a sufficient heat transfer to the feedstock, but for the DELTA-Gun no secondary gas was applied due to the formation of black depositions with a consistency of soot when hydrogen was applied. To guarantee an adequate shielding effect in the case of argon shroud gas on one hand and an effectual entrainment of nitrogen for reactive spraying of the feedstock on the other, high shroud gas flows of 90 SLPM were applied for spraying with both guns.
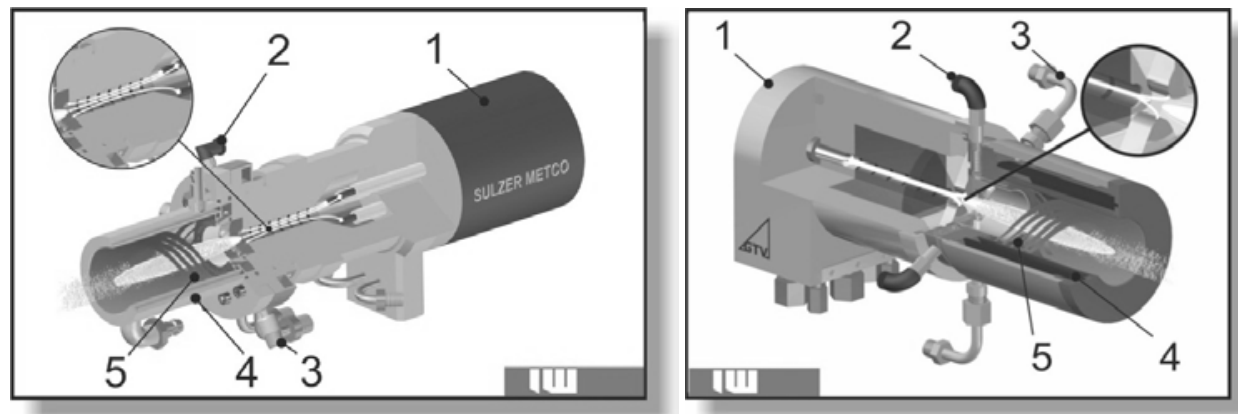

Fig. 14. 3D sectional view of the shroud modules of Triplex (top) and DELTA-Gun (bottom): 1 Gun, 2 shroud gas inlet, 3 powder injector, 4 water-cooled shroud, 5 helical injected shroud gas

\begin{tabular}{|l|c|c|}
\hline Parameter & Triplex & DELTA-Gun \\
\hline Argon flow & $35 \mathrm{slpm}$ & $40 \mathrm{slpm}$ \\
\hline Helium flow & $20 \mathrm{slpm}$ & - \\
\hline Current & $250-350 \mathrm{~A}$ & $210-330 \mathrm{~A}$ \\
\hline Plasma brut powers & $36 \mathrm{~kW}-51 \mathrm{~kW}$ & $24-48 \mathrm{~kW}$ \\
\hline $\begin{array}{l}\text { Spraying distance } \\
\text { (shroud/substrate) }\end{array}$ & $10 \mathrm{~mm}$ & $10 \mathrm{~mm}$ \\
\hline Traverse speed & $48 \mathrm{~m} / \mathrm{min}$ & $48 \mathrm{~m} / \mathrm{min}$ \\
\hline Shroud gas flow & 90 SLPM & 90 SLPM \\
\hline
\end{tabular}

Table 7. Parameters for Shrouded Plasma Spraying

The obtained coatings microstructures are illustrated in Figure 15. The micrographs on the left hand side show coatings sprayed in an inert atmosphere of argon, the ones on the right hand side the results of reactive spraying using nitrogen. The coatings of a and b were sprayed using the Triplex gun, whereas for spraying of the coatings $\mathrm{c}$ to $\mathrm{f}$ the DELTA-Gun was used. When spraying in inert atmosphere, the coatings show a uniformly and homogenous microstructure with a level of porosity comparable to conventional plasma 
sprayed coatings. Otherwise when nitrogen is supplied, coatings with high levels of open cavities and microstructures comparable to metallic sponges are built. This is supposedly due to a turbulent entrainment of the nitrogen shielding gas when the feedstock reacts towards the nitride. To proof the existence of the aspired nitride phases, semi-quantitative measurements by means of energy dispersive x-ray analysis (EDX) were performed on coatings sprayed with the Triplex. The results revealed contents between approximately 13 and 17 at.- $\%$ nitrogen. Further on, the nitrogen contents of the coatings were investigated using a N/O/H-Analyser (LECO Instruments Corp, St. Joseph/USA). Unfortunately the contents of nitrogen in the titanium coatings could not be measured to the high melting point of the titanium nitride, but for the chromium coating (section $\mathrm{f}$ ) the nitrogen content was determined to account for approximately 10 at.-\%.

The existence of the nitride hard phases was also verified by indentation hardness measurements. When spraying the titanium with argon as shrouding gas, mean hardness values of $360 \mathrm{HV} 0.1$ in case of the Triplex and $270 \mathrm{HV} 0.1$ for the DELTA-Gun were measured. Otherwise with the employment of nitrogen significantly higher maximum values of more than 1200 and 1000 HV 0.1 were detected.
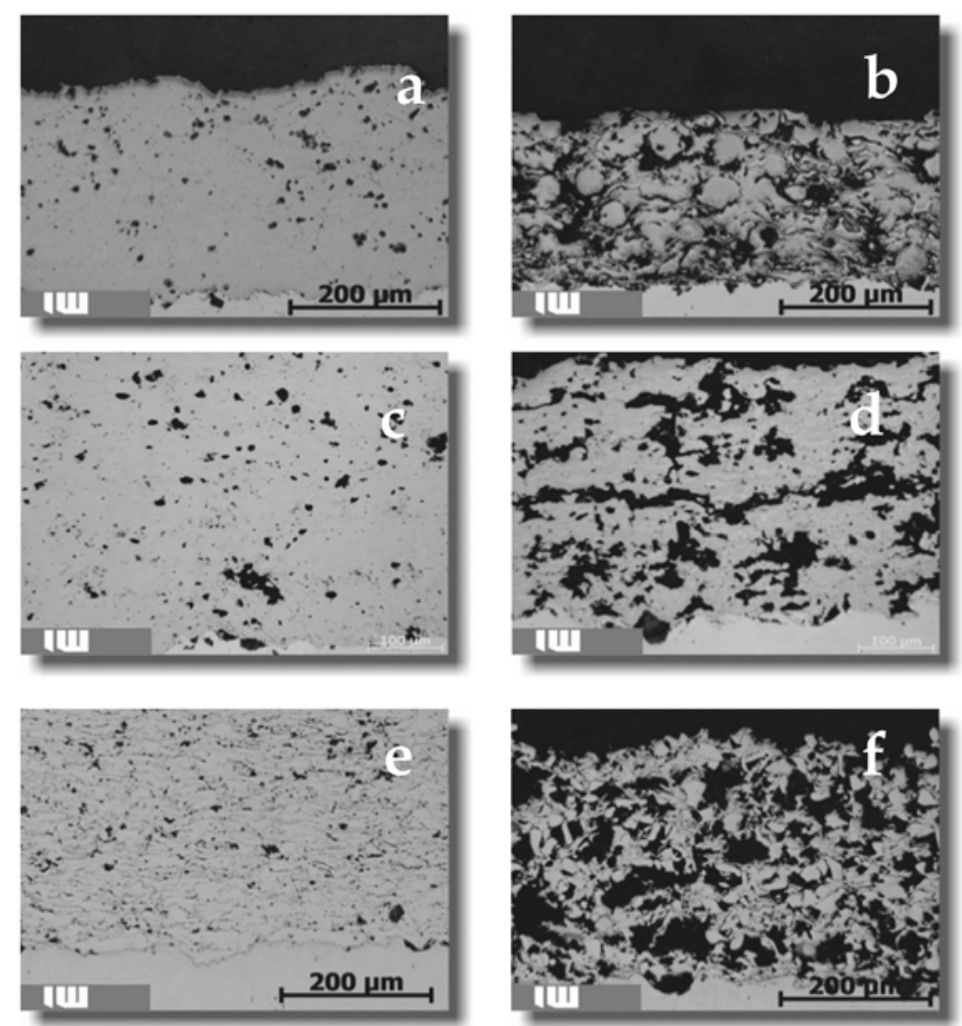

Fig. 15. Micrographs of shrouded plasma sprayed titanium (field a - d) and chromium (field $\mathrm{e}+\mathrm{f}$ ) feedstock using argon (left hand side) and nitrogen (right hand side) as shroud gas 
To characterize the adhesion of the coating systems tensile adhesive tests according to DIN EN 582 on grid blasted 1.4301 substrates were conducted. Again slightly better values were achieved for the coatings sprayed with the Triplex-II gun, as the mean values of more than $50 \mathrm{MPa}$ were measured for the titanium coatings compared to approximately $35 \mathrm{MPa}$ for both the titanium and the coarsely grained chromium feedstock when spraying was performed with the DELTA-Gun. This might be due to the problems of injecting the feedstock in the case of the DELTA, as the gun uses a gas flow supporting the cooling of the anodes. Together with the plasma and the shrouding gas, the gas throughputs through the shroud module are high and a proper feedstock injection is not easily achieved. Therefore, further optimization potential is given for the shrouded spraying in case of the DELTA-Gun. Otherwise when using the fine fractionated chromium feedstock, the tensile adhesion of the coatings reach nearly $50 \mathrm{MPa}$, comparable to the coatings sprayed with the titanium feedstock with the Triplex gun.

When spraying the titanium on polished substrates instead of the grid blasted samples, even higher tensile adhesive strengths of nearly $60 \mathrm{MPa}$ were measured. This result being not expected is probably due to diffusion phenomena of the titanium into the austenitic substrate. The effect was not recorded when using ferritic steels. In Figure 16 the backscattered electron micrograph (left hand side) and an EDX line scan analysis (right hand side) of the interface section of a titanium coating on 1.4301 steel substrate is shown. The EDX analysis confirms the findings of a zone of some micrometers depth, in which the titanium diffused. It can be stated as remarkable result, that with the limited heat transfer to the substrate enough potential is given for the diffusion process. This is due to the high diffusion coefficients of both titanium and chromium in 1.4301 austenitic steel (Kale, G.; 1998).

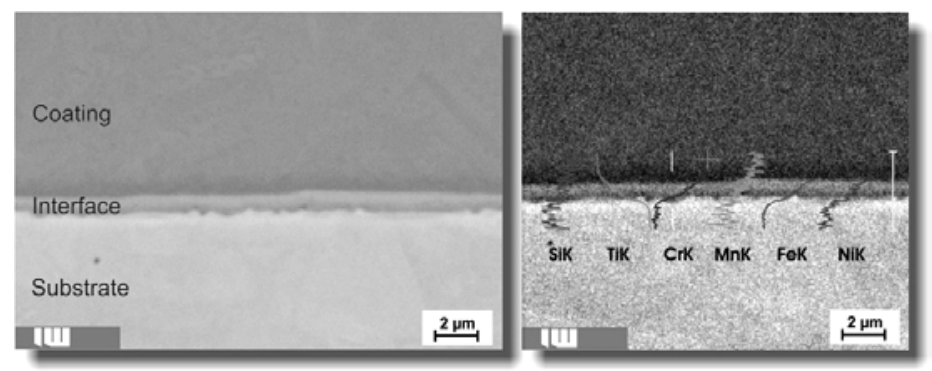

Fig. 16. BSE image of the interface of a titanium coating on 1.4301 austenitic steel (left) and corresponding EDX line scan (right hand side)

To investigate the alteration of the feedstock in the suspension plasma spraying process, Indium-Tin-Oxide (assumed composition of 9:1) was suspension plasma sprayed. ITO is used to coat glass for electrically conductive coating beeing transparent in the visible spectrum. The coatings are commonly deposited by sol-gel methods and are used in touchscreen purposes. The goal was to reach thin optical transparent ITO coatings showing electrical conductance. When overheating the feedstock it tends to build coatings with a yellowish color, whereas the coating system shows no conductance when it is not uniformly deposited. To find optimal conditions the relevant parameters (solid content of feedstock, species of the outer phase, injection conditions, applied amperage and spraying distance) 
were varied. The melting behavior of the feedstock was tested with wipe tests (see SEM images on top of Figure 17).

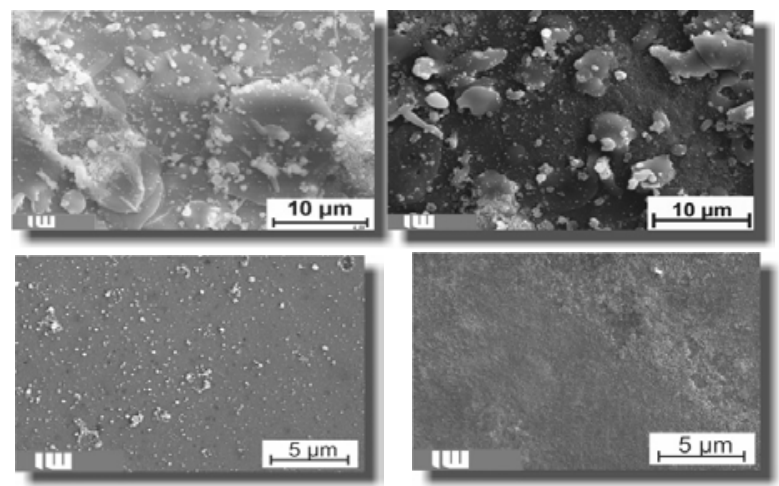

Fig. 17. SEM images of wipe tests of suspension plasma sprayed ITO feedstock and top views of ITO coatings (Triplex-II left side, DELTA-Gun on the right hand side)

With optimized parameter sets the coatings were sprayed on slides of borosilicate glass with both plasma guns. The coatings were uniformly deposited (see top view SEM images in Figure 17), showing homogenous structures. The coatings were measured by a project partner regarding their thickness and electrical conductance. It could be proven, that coatings with a thickness of approximately $400 \mathrm{~nm}$ and a sheet resistance of $850 \Omega$ could be achieved.

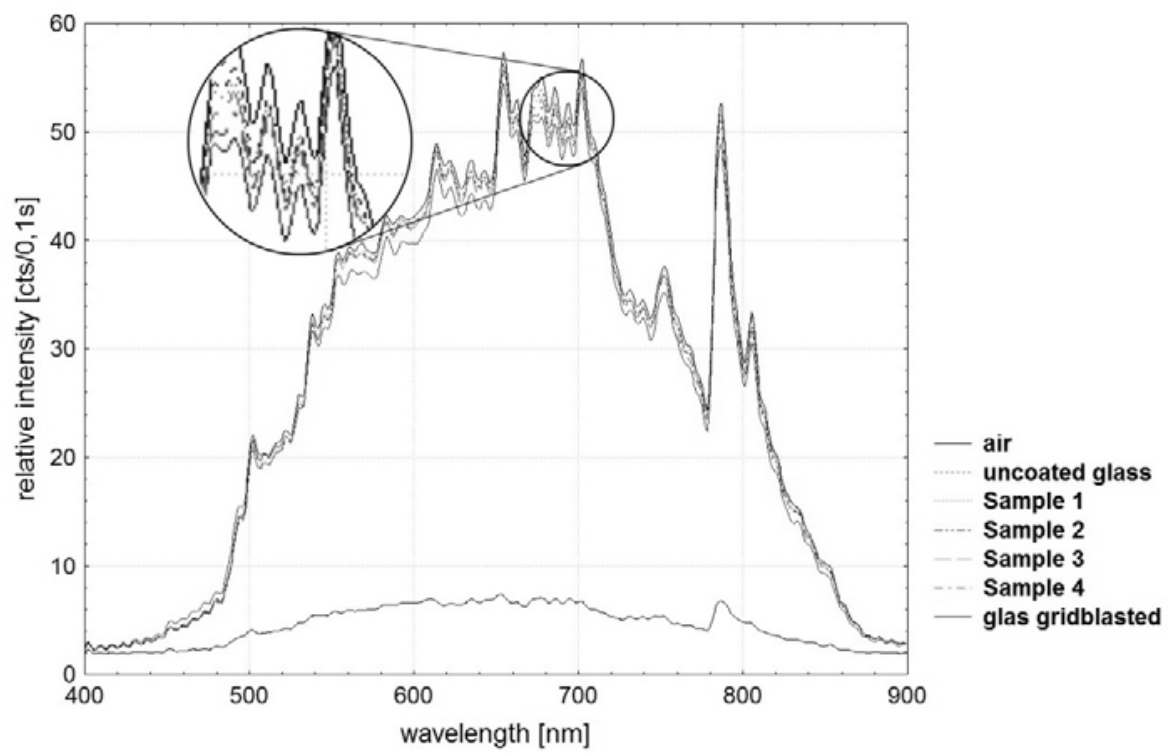

Fig. 18. Transmission spectra of four ITO coated glass slides compared to uncoated and grid blasted glass 
To determine the optical transparency of the coatings, four samples were measured using a VIS-spectrometer and the results were compared to uncoated and grid blasted glass (see transmission spectra in Figure 7). As source the tungsten lamp of the calibration module of a Tecnar DPV-2000 was used delivering a stable spectrum covering the whole visible range. The coated samples show a high degree of transparency over the whole visible spectrum. For example in the red range below $700 \mathrm{~nm}$ (see marking), the relative intensity measured is maximal 1 to 3 counts lower than that of the uncoated glass. This equals to a grade of transparency of 95 to $98 \%$. It can be stated, that both requirements regarding the electrical conductance as well as the optical transparency of the coatings systems were fulfilled. These findings show, that by suspension plasma spraying new coating systems can be realized in fields of operation, where up until now coating deposition processes like CVD and PVD are used.

\subsubsection{Summary}

With the adaption of shroud gas modules to the multieletrode plasma guns Triplex-II and DELTA-Gun it could be proven, that the spraying feedstock being susceptible to chemical reactions can both sprayed in inert atmospheres using argon and reactively sprayed by applying nitrogen as shrouding gas. The inert conditions led to the formation of coatings showing a homogenous microstructure comparable to conventionally APS sprayed metallic coatings. In the case of the use of nitrogen, no dense coatings could be achieved, but the presence of nitride phases in the coatings could be proven. Further on by means of suspension plasma spraying glass was coated with electrically conductive coatings reaching optical grades regarding their transparency. These efforts show that by means of plasma spraying new coating systems can be achieved.

\section{Acknowledgements}

The workings carried out for this contribution where funded by the German Research Foundation under the reference numbers BA 851/93-1 and SPP 1299 BA 851/94-1) and the $\mathrm{AiF}$ Arbeitsgemeinschaft industrieller Forschungsvereinigungen „Otto von Guericke“ e.V (IGF Nos. $14.509 \mathrm{~N}$ and $16.411 \mathrm{~N}$ ). This support is gratefully acknowledged by the authors.

\section{References}

Anderson, S. and Tilley, R. J. D. (1972). Crystallographic shear and non-stoicheiometry, in: Roberts, M. W. and Thomas, J. M. (eds.): Surface and Defect Properties of Solids, The Chemical Society, London, 1972, ISBN 978-1-84755-696-7

Andersson, S., Sundholm, A. \& Magnéli, A. (1959). A Homologous Series of Mixed Titanium Chromium Oxides $\mathrm{Ti}(\mathrm{n}-2) \mathrm{Cr} 2 \mathrm{O}(2 \mathrm{n}-1)$ Isomorphous with the Series $\mathrm{Ti}(\mathrm{n}) \mathrm{O}(2 \mathrm{n}-1)$ and $\mathrm{V}(\mathrm{n}) \mathrm{O}(2 \mathrm{n}-1)$, Acta Chemica Scandinavica, Vol. 13 (1959), pp. 989-997

Bauser, M.; Sauer, G. and Siegert, K. (eds., 2006). Extrusion, ASM International, Ohio, second edition, 2006, ISBN 978-0-87170-837-3

Barbezat, G. (2006). Thermal Spray Coatings for Tribological Applications in the Automotive Industry, Advanced Engineering Materials, Vol. 8 (2006), No. 7, pp. 678-681

Bolelli, G., et al. (2009). Deposition of TiO2 Coatings: Comparison between High Velocity Suspension Flame Spraying (HVSFS), Atmospheric Plasma Spraying and HVOF- 
spraying, in: Proc. of the ITSC 2009, 04.-07. May 2009, Las Vegas, ISBN 978-1-61503004-0

Dean, A. M. \& Voss, D (1999). Design and Analysis of Experiments, Springer, ISBN 978-0-38798561-9, Berlin, Germany, DOI: 10.1007/b97673

Fauchais, P. et al. (2008). Parameters Controlling Liquid Plasma Spraying: Solutions, Sols, or Suspensions, Journal of Thermal Spray Technology, Vol.17 (2008), No. 31, pp. 31-59

Gardos, M. N. (1988). The Effect of Anion Vacancies on the Tribological Properties of Rutile (TiO2-x). Tribol. Trans. Vol. 31(4), 1988, pp. 427-455

Gell, M., et al. (2001). Development and implementation of plasma sprayed nanostructured ceramic coatings. Surface and Coatings Technology, Vol. 146-147 (2001), pp. 48-54

Goldschmidt, V. M. (1926). Die Gesetze der Krystallochemie, Naturwissenschaften, Vol. 14 (1926), No. 21, pp. 477-485, in German

Hawk, D. and Müller, F. (1980). Thermochemie des Systems CoO-B2O3, Z. anorg. allg. Chem., Vol. 466 (1980), pp. 163-170, in German

Heimann, R.B. (2008). Plasma Spray Coating - Principles and Applications, pp. 389. WILEYVCH Verlag, ISBN 978-3-527-32050-9, Weinheim, Germany

Kale, G. (1998). Interdiffusion studies in titanium 304 stainless steel system. Journal of Nuclear Materials, Vol.257, No.1, (1998), pp. 44-50, ISSN 0022-3115, DOI: http:/ / dx.doi.org/10.1016/0022-3115(88)90072-4

Lugscheider, E. \& Bach, Fr.-W. (eds., 2002). Handbuch der thermischen Spritztechnik.: Technologien - Werkstoffe - Fertigung, Verlag für Schweißen und Verwandte Verfahren, DVS-Verl., ISBN 3871551864, Düsseldorf, Germany

Mason, R. L. et al. (2003). Statistical Design and Analysis of Experiments, John Wiley \& Sons, ISBN 9780471372165, Hoboken, NJ, USA, DOI: 10.1002/0471458503

Matthäus, G., Wolf, J. \& Ackermann, D. (2010): Near-net-shape HVOF coating and finishing techniques for highly stressed components in aircraft industry, Proceedings of the International Thermal Spray Conference 2010, ISBN 978-3-87155-590-9, May 03 - 05 2010, Singapore

NIST (July 2011). NIST/SEMATECH e-Handbook of Statistical Methods, 01. July 2011. Available from: <http://www.itl.nist.gov/div898/handbook/>

Paul, A. (1975). Activity of nickel oxide in alkali borate melts, Journal of Materials Science, Vol. 10 (1975), pp. 422-426

Phadke, M. S. (1989). Quality Engineering Using Robust Design, Prentice Hall, ISBN 9780137451678, New Jersey, USA

Shannon, R.D. (1976). Revised effective ionic radii and systematic studies of interatomic distances in halides and chalcogenides, Acta Cryst. A, Vol. 32 (1976), pp. 751767

Tilmann, W. et al. (2008a). Influence of the HVOF gas composition on the thermal spraying of WC-Co submicron powders $(-8+1$ micron) to produce superfine structured cermet coatings. Journal of Thermal Spray Technology, Vol.17, No.5-6, (2008), pp. 924932, ISSN 1059-9630

Tilmann, W. et al. (2008b). Near-Net-Shape and Dense Wear Resistant Thermally Sprayed Coatings. Key Engineering Materials, Vol.384-384 (2008), pp. 117-123, ISSN 10139826 
Tombs, N. C.; Croft, W. J. \& Mattraw, H. C. (1963). Preparation and Properties of Chromium Borate, Inorg. Chem. 2, Vol. 4 (1963), pp. 872-873

Wood, G. J. et al. (1982). Mechanism of oxidation of the crystallographic shear phase Ti4O7, Philosophical Magazine A, Vol. 46, (1982), No. 1, pp. 75-86 


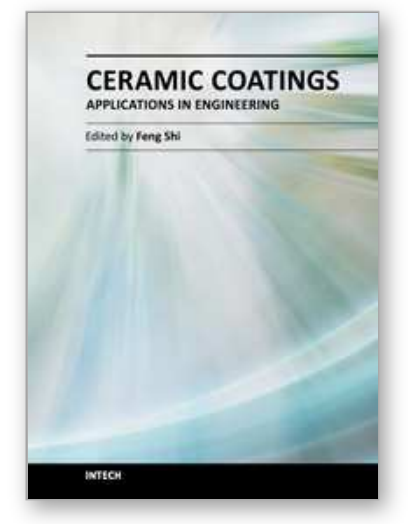

\author{
Ceramic Coatings - Applications in Engineering \\ Edited by Prof. Feng Shi
}

ISBN 978-953-51-0083-6

Hard cover, 286 pages

Publisher InTech

Published online 24, February, 2012

Published in print edition February, 2012

The main target of this book is to state the latest advancement in ceramic coatings technology in various industrial fields. The book includes topics related to the applications of ceramic coating covers in enginnering, including fabrication route (electrophoretic deposition and physical deposition) and applications in turbine parts, internal combustion engine, pigment, foundry, etc.

\title{
How to reference
}

In order to correctly reference this scholarly work, feel free to copy and paste the following:

Martin Erne and Daniel Kolar (2012). Thermal Spraying of Oxide Ceramic and Ceramic Metallic Coatings, Ceramic Coatings - Applications in Engineering, Prof. Feng Shi (Ed.), ISBN: 978-953-51-0083-6, InTech, Available from: http://www.intechopen.com/books/ceramic-coatings-applications-in-engineering/thermalspraying-of-oxide-ceramic-and-ceramic-metallic-coatings

\section{INTECH}

open science | open minds

\author{
InTech Europe \\ University Campus STeP Ri \\ Slavka Krautzeka 83/A \\ 51000 Rijeka, Croatia \\ Phone: +385 (51) 770447 \\ Fax: +385 (51) 686166 \\ www.intechopen.com
}

\author{
InTech China \\ Unit 405, Office Block, Hotel Equatorial Shanghai \\ No.65, Yan An Road (West), Shanghai, 200040, China \\ 中国上海市延安西路65号上海国际贵都大饭店办公楼405单元 \\ Phone: +86-21-62489820 \\ Fax: +86-21-62489821
}


(C) 2012 The Author(s). Licensee IntechOpen. This is an open access article distributed under the terms of the Creative Commons Attribution 3.0 License, which permits unrestricted use, distribution, and reproduction in any medium, provided the original work is properly cited. 